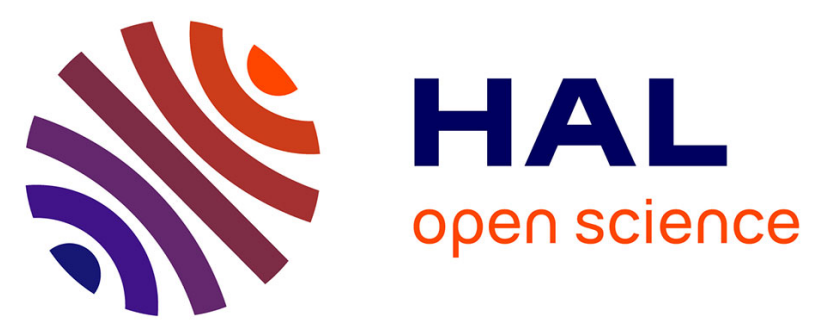

\title{
An updated archeomagnetic directional variation curve for France over the past two millennia, following 25 years of additional data acquisition
} Maxime Le Goff, Yves Gallet, Nicolas Warmé, Agnes Genevey

\section{- To cite this version:}

Maxime Le Goff, Yves Gallet, Nicolas Warmé, Agnes Genevey. An updated archeomagnetic directional variation curve for France over the past two millennia, following 25 years of additional data acquisition. Physics of the Earth and Planetary Interiors, 2020, 309, pp.106592. 10.1016/j.pepi.2020.106592 . hal03028894

\section{HAL Id: hal-03028894 \\ https://hal.science/hal-03028894}

Submitted on 27 Nov 2020

HAL is a multi-disciplinary open access archive for the deposit and dissemination of scientific research documents, whether they are published or not. The documents may come from teaching and research institutions in France or abroad, or from public or private research centers.
L'archive ouverte pluridisciplinaire HAL, est destinée au dépôt et à la diffusion de documents scientifiques de niveau recherche, publiés ou non, émanant des établissements d'enseignement et de recherche français ou étrangers, des laboratoires publics ou privés. 
1 An updated archeomagnetic directional variation curve for France over the past two

\section{millennia, following 25 years of additional data acquisition}

Maxime Le Goff ${ }^{1,}{ }^{*}$, Yves Gallet ${ }^{1}$, Nicolas Warmé ${ }^{2}$, Agnès Genevey ${ }^{3}$

${ }_{1}^{1}$ Université de Paris, Institut de Physique du Globe de Paris, CNRS, Paris, France

${ }^{2}$ Institut National de Recherches Archéologiques Préventives, La Courneuve, France

3 Sorbonne Université, CNRS, Laboratoire d'Archéologie Moléculaire et Structurale, Paris, France

Abstract

Nearly 40 years ago, Emile Thellier published an article summarizing the archeomagnetic data he had obtained during his career, which had allowed him to recover the main features of the directional variations of the geomagnetic field in France for the last two millennia. This database went on to be significantly completed 25 years ago by Ileana Bucur, who had taken over Thellier's work on archeomagnetism; this forms the current basis of our knowledge of the directional evolution of the geomagnetic field in France. Since then, archeomagnetic studies have been continued at Thellier's historical laboratory in Saint Maur. This article presents the directional archeomagnetic data obtained in France over the past 25 years in this same laboratory. A total of 528 new data are presented, which, together with the 170 results obtained on the French territory previously listed in Bucur (1994), constitute the French directional database (698 data in all). All but two of these data were obtained using the experimental protocol developed by E. Thellier based on the analysis of large samples and on a magnetic viscosity test that has proved its reliability on numerous occasions. The directions from the entire French database have been precisely defined, with 95\% of the $\alpha_{95}$ values being less than $1.9^{\circ}$, and $\sim 50 \%$ being less than $0.8^{\circ}$. The selection of 286 data with dating 
uncertainties of $\leq 50$ years allowed us to compute a new reference directional variation curve for France since the first century BC using sliding windows, the variable durations and shifts of which were adapted to the time distribution of the available data, and the bivariate extension of the Fisher statistics. This shows ample and smooth variations, fairly similar to those previously determined from a much smaller database. The resulting secular variation curve is particularly well suited for use in archeomagnetic dating.

\section{Introduction}

Archeomagnetism has developed considerably over the last 20 years. Numerous studies have led to a better understanding of the temporal variations of the geomagnetic field in different parts of the world, although these data still mainly concern the European area (e.g. Schnepp and Lanos, 2005; Gómez-Paccard et al., 2006; Martón and Ferencz, 2006; Tema et al., 2006; Batt et al., 2017; Molina-Cardín et al., 2018; Shaar et al., 2018; Schnepp et al., 2020). For metropolitan France, in particular, the last two decades have been marked by significant progress in the knowledge of directional variations during the first millennium BC (e.g. Gallet et al., 2002; Hervé et al., 2013a) and intensity variations over the past 3000 years (e.g. Chauvin et al., 2000; Genevey and Gallet, 2002; Genevey et al., 2009; 2013; 2016; Hervé et al., 2013b). In addition to the construction of regional secular variation curves, the densification of the archeomagnetic database (e.g. Korte et al., 2005; Genevey et al., 2008; Brown et al. (2015) has made it possible to construct global geomagnetic field models that encompass the last few millennia (e.g. Hongre et al., 1988; Korte and Constable, 2005; 2011; Nilsson et al., 2010; Licht et al., 2013; Pavón-Carrasco et al., 2014; Constable et al., 2016; Sanchez et al., 2016; Hellio and Gillet, 2018; Arneitz et al., 2019). All these studies have thus allowed a better characterization of the variability of the geomagnetic field on time scales ranging from a few decades to several millennia. Another reason for the recent spurt of 
development in archeomagnetism is its ability to provide original dating constraints for archeologically poorly-dated structures (e.g. Le Goff et al., 2002; Pavón-Carrasco et al., 2011; Rouzeau et al., 2015; Tema et al., 2019; Schnepp et al., 2020), as well as for a better understanding of the history of volcanoes (e.g. Tanguy et al., 2007; 2009; 2011). Whether applied to geomagnetic or archeological themes, however, archeomagnetism requires constant improvement in the accuracy and reliability of regional secular variation curves.

First of all, it should be noted that this study focused only on archeo-directional data. Research in archeomagnetism began in France in the 1930s with the pioneering work of Emile Thellier (Thellier, 1938). Combining instrumental and methodological developments, data acquisition, and the patient establishment of collaborations with archeologists, Thellier's activity led to the construction of the first directional (archeo)secular variation curve for France covering the last two millennia (Thellier, 1981). After Thellier's retirement, Ileana Bucur continued this work, enriching the French archeomagnetic database with 200 directional data, of which the 120 best dated were used to construct a revised version of the French directional variation curve from the first century BC to 1600 (Bucur, 1994). Furthermore, I. Bucur has quite often used archeomagnetism as a dating tool, which she has applied to provide dating constraints for archeological burnt structures discovered in situ and poorly dated, and which has enabled her to strengthen her collaborations with archeologists. Since Bucur's retirement (1997), the acquisition of archeomagnetic directional data has continued at the historical archeomagnetism laboratory of Saint-Maur (part of the Institut de Physique du Globe de Paris). The purpose of this paper is to present an update of the SaintMaur French archeomagnetic dataset, and of the associated reference directional secular variation (DSV) curve covering the last two millennia.

To carry out his archeomagnetic studies, Emile Thellier developed a methodology for the sampling and magnetization analysis that differed significantly from that currently used in 
paleomagnetism (e.g. Thellier, 1981). Like Ileana Bucur, we have continued to use Thellier's protocol, which was specifically adapted to the nature of the material sampled and the behavior of its magnetization. Practically all other archeomagnetic studies outside our research group are based on different paleomagnetic criteria (e.g., relying on magnetization measurements carried out on small samples and demagnetization experiments). This clearly poses a problem for the classification of the quality of the available archeomagnetic data. Despite the fact that the French dataset was compiled quite a long time ago (Bucur, 1994), the associated archeomagnetic directional variation curve has often been used as a reference for comparison with other archeomagnetic data. On the other hand, however, the individual archeomagnetic data (i.e., those obtained at the burnt structure level) are viewed with caution and classed as the lowest quality (e.g. Tarling, 1999; Brown et al., 2015). For this reason, here, we recall Thellier's experimental protocol and show its perfect adequacy for the detailed recovery of past variations in the geomagnetic field of Western Europe.

\section{An additional 25 years of archeomagnetic sampling}

We report new data obtained from 528 burnt structures from different archeological sites, giving a total of 698 directional results when including the 170 data from the ThellierBucur database strictly reduced to represent the territory of metropolitan France only (Fig. 1). The data mainly come from around Paris, in the Ile-de-France region. This uneven geographic site distribution is explained by the fact that one of us (N. Warmé) is an archeologist working at the Ile-de-France center of the Institut National de Recherches Archéologiques Préventives (INRAP). Several archeological sites were intensively sampled for archeomagnetism, such as the localities of Saint-Pathus with its 58 different kilns, and Villiers-le-Sec and Léry, with 35 burnt structures each (Fig. 1; archeological references in Table S1 and Text S1). A few other structures were sampled in eastern France (e.g. archeological sites of Wiwerschein (6 
structures), Avenay (3), Dizy (3) and Laudrefang (3)) and in southeastern France (e.g. Montpellier (6), Orgon (1)).

Of the new data, 327 are from domestic kilns. The remaining results come from pottery kilns (77), kilns for tile and brick production (26), lime kilns (17) and others (one bell founding, two drying sheds, hypocaust but also 15 cases of undetermined use). The domestic kilns, which thus represent a little less than two-thirds of the new collection, were mainly found in ancient rural settlements dating back to the High Middle Ages.

All baked clay structures were sampled using the plaster cap method described in Thellier (1967a; 1981), Bucur (1994) and Le Goff and Gallet (2019). This method consists first of isolating several large blocks of baked clay of various sizes from the best preserved and heated parts of the floor of the structure (Fig. 2a). As a very general rule, sampling only the floor of a kiln minimizes the risk of possible distortion in the distribution of magnetic directions that could be produced by wall tilting during burial or excavation. These blocks are then coated with plaster strips to preserve their cohesion (Fig. 2a,b), a practice we have adopted since the early 1990s. On top of each block, depending on its size, one or several plaster caps are molded with a large ( 10-cm-diameter) horizontal upper surface (Fig. 2b). The directions of the local magnetic north and of the sun at a given time are both precisely reported on these horizontal surfaces, the latter orientation providing the direction of the geographic north with a typical accuracy of $\pm 1^{\circ}$ (Fig. 2c,d). Note that not all the samples collected could be oriented with respect to the Sun due to adverse weather conditions. Thus, for $\sim 1 / 3$ of the analyzed structures, the local declination was given by the IGRF model at the time and location of sampling. The consolidated and oriented blocks are then removed from the structure and transported to the laboratory. There, the large blocks are cut into separate samples, each with its own plaster cap and, thus, its independent orientation. The oriented samples are finally adjusted and plastered in standard 12-cm-sided molds (Fig. 2e). 


\section{Magnetization measurements and experimental protocol}

The remanent magnetization of the standard 12-cm-sided samples was measured using a rotating inductometer, especially designed to accomodate their large size (Fig. 2f; e.g. Thellier, 1967b; Le Goff, 1975). The sizes of the instrument, the samples and the storage volume required by the number of samples make it impossible to perform the measurements in a zero-field chamber. The entire analytical procedure is performed in the laboratory field, where viscous remanent magnetization (VRM) may interfere with the thermoremanent magnetization (TRM) being sought (Thellier, 1981). We therefore perpetuated Thellier's protocol, in which a viscosity test, involving two magnetization measurements, is performed for each sample. The samples are first left for a minimum of four weeks precisely oriented in the direction of the laboratory field, i.e. in the same magnetic position as the samples had when in situ. This position is referred to as the direct position. After this time interval, the sample magnetization is considered to have 'restored' the (initial) viscous magnetisation acquired since the last cooling of the kiln, which was disturbed by the sampling and laboratory preparation. A first measurement is obtained: $\mathrm{M}_{\mathrm{dir}}$. The samples are then left again for four weeks, but situated in the opposite direction to the laboratory field (referred to as the 'reverse position'). Now, an opposite four-week VRM is acquired, replacing the four-week direct VRM and part of the initial VRM. A second measurement is taken: $\mathrm{M}_{\text {rev. }}$. From these two sets of measurements, it is straightforward to determine by vectorial addition and subtraction for each sample both the moment and direction of the TRM (with a small fraction of the initial VRM), here referred to as the $\mathrm{TRM}_{\mathrm{Th}}$ to underline the fact that it stems from Thellier's method, and the VRM acquired in four weeks. Moreover, a viscosity index (v), expressed as a percentage, is computed from the ratio of the VRM to TRM. Because VRM acquisition follows a logarithmic temporal law (e.g. Dunlop and Ozdemir, 1997), the VRM 
acquired in four weeks represents a very significant fraction of the initial VRM, and Thellier's protocol strongly reduces its parasitic effect on the directional TRM results. A more accurate positioning of the samples relative to the magnetic north in the laboratory for both the direct and reverse steps of the viscous experiments allowed us to increase the rejection viscosity threshold up to $10-12 \%$.

Several examples of VRM and TRM determinations are shown on the DeclinationInclination graphs in Fig. 3. These cases, from six different structures, make it clear that the VRM directions (black symbols in Fig. 3) are very similar to the present-day geomagnetic field direction (yellow circle), while the mean TRM directions (red symbols) form clusters which differ significantly from each other due to the different ages of the structures ranging from the High Middle Ages period to the modern period.

The viscosity test used proved to be very effective in isolating the primary TRM direction and attesting to its stability (e.g. Bucur, 1994). This is the case because we only studied short-lived structures, which were abandoned and rapidly buried after their last use, which strongly limits the possibility of secondary magnetization acquisition (except VRM) due, for instance, to partial re-firing. It is worth pointing out that the magnetic viscosity experiments were used here as a 'cleaning' method, similarly to the thermal or alternatingfield demagnetization treatments used in paleomagnetism to analyze the often complex magnetic behavior of much older rocks, or in archeomagnetism on volcanics, in which lightning is a frequent cause of the acquisition of parasitic isothermal remanent magnetization (IRM; e.g. Tanguy et al. 2011). In this respect, the directions obtained for the VRM-cleaned TRM clearly cannot be considered simply equivalent to the directions of natural remanent magnetization (NRM).

Figure 4a,b shows examples of alternating-field (AF) demagnetization up to 20-30 mT performed on two series of large samples, together with the results obtained on the same 
samples using the Thellier protocol before their AF demagnetization. Fig. 4a presents the data from 11 samples collected in the archeological site of Tremblay (Ile-de-France region). The mean direction determined by principal component analysis of the AF demagnetization data (Dec. $=6.9^{\circ}$, Inc. $=72.2^{\circ}, \mathrm{K}=2182$ with $\mathrm{N}_{\text {sample }}=11$ and $\alpha_{95}=0.9^{\circ}$ ) is identical with a $95 \%$ confidence level $\left(\gamma=0.7^{\circ}, \gamma_{c}=1.3^{\circ}\right.$; McFadden and McElhinny, 1990) to that obtained using the Thellier protocol (Dec $=6.3^{\circ}$, Inc $=71.5^{\circ}, \mathrm{K}=2214$ with $\mathrm{N}_{\text {sample }}=11$ and $\alpha_{95}=0.9^{\circ}$; the yellow dots show the individual $\mathrm{TRM}_{\mathrm{Th}}$ directions). The data from the archeological site of Varennes displayed in Fig. 4b illustrate a case where AF demagnetization of four samples was carried out quite a long time after the determination of their $\mathrm{TRM}_{\mathrm{Th}}$ directions. It can be seen that $\mathrm{AF}$ demagnetization makes the directions clearly converge towards the VRM-cleaned TRM directions, showing that AF demagnetization removes the viscous remanent magnetization, which was well taken into account by the Thellier protocol. Fig. 4c illustrates a comparison between data from the same archeological site (at Saint-Gilles-du-Gard in southern France), assumed to be of the same age, but obtained after sampling carried out at 35-year intervals (1972/2007), subjected to Thellier's protocol (1972) and the classical paleomagnetic method including thermal demagnetization and TRM anisotropy correction (P. Lanos and J. Thiriot, personnal communication 2011). The two series of three data give mean directions (after transfer to Paris's coordinates, Thellier: Dec. $=11.4^{\circ}$, Inc. $=56.2^{\circ}, \mathrm{K}=1037$ with $\mathrm{N}_{\text {sample }}=18$ and $\alpha_{95}=1.0^{\circ}$; Lanos-Thiriot: Dec $=12.4^{\circ}$, Inc $=57.1^{\circ}, \mathrm{K}=519$ with $\mathrm{N}_{\text {sample }}=50$ and $\alpha_{95}=0.9^{\circ}$ ) that are identical at the 95\%-confidence level $\left(\gamma=1.1^{\circ}, \gamma_{\mathrm{c}}=1.6^{\circ}\right.$; McFadden and McElhinny, 1990), which further testifies to the effectiveness of Thellier's approach.

It is also important to mention the possible effects of magnetic anisotropy. Magnetic anisotropy disturbs the recording fidelity of the geomagnetic direction in two ways: by mechanical action during the manufacture of bricks or tiles (structural or fabric anisotropy) or by the magnetization of the kiln itself (anisotropy of the demagnetizing field also referred to 
as magnetic refraction; e.g. Aitken and Hawley, 1971; Thellier, 1981; Lanos, 1987). The first is mainly because, before firing, the clay has been stretched for moulding, while the second is due to the rather thin and elongated dimensions of the magnetized clay layers.

We practically always avoided collecting samples from bricks or tiles found in the kilns. The latter, although (re)-fired during kiln use, could still carry a certain fraction of the primary magnetization they acquired during their manufacture. More importantly, it should be noted that a large proportion of our new results come from domestic kilns dug directly into the ground, in which the original silt was left in place without any moulding. On a single occasion, samples were taken from two brick fireplaces excavated at the Morimond Abbey (Rouzeau et al., 2015). In both cases, small samples were carefully prepared and oriented from the bricks, fully thermally demagnetized (with the recovery of two partial-TRM magnetization components) and corrected for TRM anisotropy. Otherwise, we only analyzed samples in which the magnetization is generally considered to be structurally highly isotropic using Thellier’s protocol (e.g. Evans and Hoye, 2005; Kovacheva et al., 2009).

On the hand, the effect of the demagnetizing field is very difficult to evaluate and, above all, it cannot be corrected experimentally (unless an equivalent firing of a similar structure/surface, made of the same natural clay, is performed and the resulting samples are collected from the very same zones). This effect depends on the nature and grain size of the magnetic mineralogy and the intensity of the magnetizations (the higher the intensity, the greater the effect), which vary from kiln to kiln. If present in a kiln, the demagnetizing field effect can only be attenuated by taking numerous samples from the entire kiln structure (e.g. Thellier, 1981; Schurr et al., 1984; Soffel and Schurr, 1990). We mainly sampled the bottom of the kilns; it therefore cannot be excluded that our archeomagnetic directions (and the resulting curve presented below) are slightly biased in inclination (e.g. Schurr et al., 1984); however, it should also be noted that the magnetization in the kilns studied was generally on 
the order of $0.1-1.0 \mathrm{~A} / \mathrm{m}$, which is less prone to significant magnetic refraction (e.g. Kovacheva et al., 2009).

\section{Description of the new archeo-directional results}

Approximately two-thirds of the new archeomagnetic data were obtained for archeomagnetic dating purposes, as the structures concerned had substantial archeological dating intervals (>100-400 years), On the other hand, the results from 140 burnt structures were dated using archeological constraints, in particular from the typo-morphology of ceramics, coins and archives, with sufficient precision and accuracy to be used to improve the French reference directional secular variation curve for the past two millennia (archeological references in Table S1 and Text S1, and see below). All data obtained from dated and poorlydated or undated burnt structures are reported in Table S1 in Electronic Supplement, including those from the Bucur (1994) database, with a few updates due either to subsequent improvements in the dating of the kilns studied or to the dissociation of some datasets that had been grouped together in the original publication (Table 1 in Bucur, 1994).

Most of the structure-averaged viscosity index values for these data are between $6 \%$ and $8 \%$, with a mean viscosity of $\sim 6.0 \%$ (Fig. $5 a$ ), and with a typical range of $\sim 2 \%$ at the sample level per structure. The mean is higher than that of Bucur (1994)'s original database $\left(v_{\text {mean }}=3.3 \%\right)$. This difference is due to the much greater number of data obtained from domestic kilns that were added to that database: the viscosity values from 81 artisan (pottery, tile, lime) kilns are among the 100 lowest viscosity indices $\left(v_{\text {mean }}=2.6 \%\right)$, whereas the viscosity values from 89 domestic kilns are among the 100 highest values ( $\left.v_{\text {mean }}=9.4 \%\right)$. This probably reflects higher temperatures being reached in artisan kilns. It should be noted that the magenta bars in Fig. 5a show the number of results referred to as abnormal values and 
rejected by Bucur (1994), to which six new data were added. Each of these six data deviates significantly from the age-corresponding segment of the mean DSV curve that we calculated (see below), with a minimum angular distance to the curve of $\sim 6^{\circ}$, up to $\sim 10^{\circ}$. These are the largest angular distances, whereas most of them (i.e. for $\sim 94 \%$ of the database) are $<3^{\circ}$. The mean TRM directions are particularly well defined, with large Fisher precision parameters (averaging 4253) and small $\alpha_{95}$ (averaging $\sim 0.9^{\circ}$ ). In 95\% of the cases, the $\alpha_{95}$ values are less than $1.8^{\circ}$, with $\sim 50 \%$ being less than $\sim 0.8^{\circ}$ (Fig. 5 b). Twelve structures provided very small $\alpha_{95}$ values of less than $0.4^{\circ}$ (minimum of $0.24^{\circ}$ ) and Fisher parameters up to 32335 (Table S1). Nevertheless, it should be borne in mind that such a high degree of precision is not necessarily a guarantee of data reliability with respect to the geomagnetic field at the given time. It should also be mentioned that, excluding the rare $\alpha_{95}$ values $>2^{\circ}$, there is no clear systematic relationship between the $\alpha_{95}$ values and the associated numbers of samples (Fig. S1a), which means that the small $\alpha_{95}$ values are not only the result of a statistical accumulation of data by structure, but they also attest to the quality of the mean direction determinations.

Figure 6 shows the changes in the temporal distribution of the data between the Thellier-Bucur database (Fig. 6a), the new data (Fig. 6b) and the combination of the two datasets retaining only those data (286 values) with dating uncertainties of $\leq 50$ years (Fig. 6c). Although the results from the Thellier-Bucur's database cover all periods from the last two millennia, these are unevenly distributed in time, being concentrated maintly during the Roman period and the Middle Ages after $~ 900$ AD (Fig. 6a). The results from other periods were much rarer, especially from between $\sim 400$ and $~ 900$ AD. On the other hand, the age distribution of the new data is strongly biased in favor of the High Middle Ages (with 383 new data from between $~ 500$ and $~ 1000$ AD compared to the previous 47 ), but unfortunately often with significant age uncertainties (Fig. 6b; see also Fig. S1b and Fig. S2a,b showing the 
histogram of the dating uncertainties and the time distribution of the declinations and inclinations of all available data, respectively). The age distribution of all the data with dating uncertainties of $\leq 50$ years, however, is quite homogeneous, although there is still less data for the 5th and 15th centuries, and practically no data for after 1700 (Fig. 6c; see also Fig. S3).

The available archeomagnetic directions are illustrated on spherical projections in Fig. 7. All 698 mean directions are shown in Fig. 7a with a color code depending on the $\alpha_{95}$ values, and with a change in color signifying a change in the circled areas by a factor of 3 , where white $<0.5^{\circ} \leq$ yellow $<0.9^{\circ} \leq$ brown $<1.5^{\circ} \leq$ green $<2.6^{\circ} \leq$ blue. The data with the smallest $\alpha_{95}$ values are visibly distributed close to each other and appear to show a preferential path, although no age constraints are provided at this stage. This preferential path is reinforced when a color code is used to specify the dating of the data (but without any further trend calculation). Here, each $\alpha_{95}$ circle is colored according to its central date, with a gradation corresponding to its date range. In Fig. 7b,c, the data have been separated into two time intervals, between $100 \mathrm{BC}$ and 1000 AD (Fig7b) and between 1000 AD and 1900 AD (Fig. 7c), in order to avoid confusion resulting from crossing directions around an inclination of $\sim 70^{\circ}$ and a declination of $\sim 0^{\circ}$. In particular, this distinction makes a preferred path after 1000 AD more evident (Fig. 7c). On the other hand, the representation chosen in Figs. 7a,b,c suggests that selection of the best-dated data (with dating uncertainties of $\leq 50$ years) did not significantly change the above-mentioned observations (Fig. 7d,e,f), but rather seems to tighten the preferential path (for instance compare Fig. 7b and Fig. 7e; see section 5.1 for further discussion).

It is also interesting to separately illustrate several archeomagnetic datasets obtained from different archeological sites, where a fairly large amount of data had been obtained from each of them. Fig. 8 highlights such a situation for three different archeological sites. It can be seen that each dataset describes a certain segment of secular variation marked by a coherent 
pattern of directions, mainly with variations in inclination for the Saint-Pathus data (Fig. 8a; Desrayaud, 2010; Hurard, 2011), in declination for the Villiers-le-Sec data (Fig. 8b; Gentili, 2000) and in both declination and inclination for the Evreux data (Fig. 8c; Jego, 2010). Independently of their exact dating, these different datasets therefore provide a test of consistency at the archeological-site level for the construction and robustness of the French secular variation curve. The interest in archeology is no less important as a large dataset allows analysis of the occupation phases of an archeological site (duration of the total occupation, discontinuities in occupation, etc.). Although beyond the scope of this study, it should be noted that this aspect of archeomagnetism, based on dense sampling, has generated much interest and effort within our group over the past 25 years.

\section{Discussion}

\subsection{On the need to select the best-dated results}

Le Goff and Gallet (2019) recently illustrated the limitations of the resolution of a regional mean DSV curve resulting from the accuracy of the archeomagnetic data used to construct the curve. This precision relates to both the accuracy of the directions (as expressed by their $\alpha_{95}$ values) and the uncertainties about their dating. The latter uncertainties clearly play a major role in undermining the resolution (see also discussion in Tarling and Dobson, 1995). To recover all the variability of geomagnetic directions expected for the latitudes of metropolitan France, as can be deduced from the gufm1 model (Jackson et al., 2000; Le Goff and Gallet, 2019), the archeomagnetic data would require, on average, a dating accuracy of $\sim 10$ years, which is far beyond any reality (and any hope) given the archeological constraints very generally applicable to the structures studied. The abundance of data, from incorporating a large number of data with large age uncertainties, does not make it possible to alleviate this 
difficulty (there is rather a risk of accentuating it), making it preferable to retain only the bestdated results. It is this selective approach that we choose, retaining only the data with dating uncertainties of $\leq 50$ years.

To further illustrate this point and to complement the information provided by Fig. 7 , Fig. 9 shows the available data for two time intervals, between central dates of 450 and 750 AD (Merovingian period; Fig. 9a,b) and between 1000 and 1300 AD (Middle Age; Fig. 9c,d), with and without data with dating uncertainties of $>50$ years (Fig. 9a resp. Fig. 9b; Fig. 9c resp. Fig. 9d). As in Fig. 7, the $\alpha_{95}$ areas were colored according to the date of the data, with a color scale adjusted to their dating uncertainties. It is remarkable how data selection reduces the elongation of the distribution of directions. From Fig. 9a,b, it is obvious that some of the less well dated directions are posterior to the Merovingian period, most probably being dated to the posterior Carolingian period spanning between 751 and the end of the 10th century (which, it should be noted, is not incompatible with the archeological constraints considered). A similar situation is observed for the results dated between 1000 and 1300 AD (Fig. 9c,d), with some directions being probably either too old or too young in relation to the time segment considered when the dating uncertainties are too large.

Thus, thanks to the data selection performed, we can approach a reference DSV curve with a better resolution; however, it should be borne in mind that the latter remains insufficient for tracing details of the rapid directional variations, on the scale of a century or two, that may have occurred in France over the past few millennia (Le Goff and Gallet, 2019).

\subsection{Method for a revised French DSV curve}

We used the same method developed by Le Goff et al. (2002) to revise the DSV curve. There are two important and useful aspects to this method. The first aspect is that it involves 
sliding windows, with durations and time shifts that could be adjusted to accommodate the variable distribution of the data over time. Taking into account the mean dates and dating uncertainties of the individual archeomagnetic data, this amounts to adapting the temporal resolution of the DSV curve, i.e. without considering a uniform regularization, to give an objective view of the current knowledge of temporal variations. The second aspect is that the directions are treated vectorially, in a way very close to that which led to the determination of the different directions themselves (i.e., by using Fisher's statistics). The bivariate calculation takes into account the angular variances of all individual results (as given by their Fisher's K parameters), which means that the higher the dispersion, the larger the $\alpha_{95}$ value for the window-mean direction. The 95\%-confidence ellipses then contain relevant information both on the dispersion of the data for a certain time window and on the geomagnetic field evolution during this same time interval. It should also be noted that the method of Le Goff et al. (2002) was designed to use the reference DSV curve for archeomagnetic dating purposes. For this reason, it preserves as much as possible a good statistical consistency between the archeomagnetic directions defining the reference curve and any individual direction needing to be dated.

In the method of Le Goff et al. (2002), the duration of each time window is set according to a statistical weight that is a function of the number of data points present in the window and the proportion of time each data point spends in the window relative to its dating interval. When the DSV curve is calculated, the size of each window is increased from a minimum of 20 years (with a maximum of 110 years) until its statistical weight (i.e., the density of the data) reaches a required minimum value, which, in our study, was chosen as 8 (the same value was considered by Le Goff and Gallet, 2019). It should be noted that the minimum statistical weight was 2.5 when a set of 110 directions from the Thellier-Bucur database was used by Le Goff et al. (2002) to calculate the previous French DSV curve 
between 0 and $\sim 1600$. On the other hand, the time shift between two consecutive windows is such that the beginning of the younger window is the central date of the older window. The offset between the central dates of the two windows may then increase with the time extension of the most recent window (i.e., in order to reach the minimum statistical weight). A more detailed description of the method can be found in Le Goff et al. (2002).

For each time window, a mean archeomagnetic direction is calculated, after weighting the individual data, using the bivariate extension of Fisher's statistics (Le Goff, 1990; Le Goff et al., 1992). In this calculation, unless a bias is introduced by one or a few deviating directions present in a window, the elongation of each 95\%-confidence ellipse provides information on the direction and speed of the geomagnetic field drift through the duration of the time window in question.

\subsection{Description and comparison of the revised French DSV curve with the previous curve}

Sixty-four successive time windows were isolated between 100 BC and 1700 AD. Fig 10a shows that they all have approximately the same statistical weight, mainly between 8 and 10 , and that their mean duration is $\sim 60$ years. The resulting DSV curve is displayed on a spherical projection in Fig. 10b (red-white line with the 95\%-confidence ellipses in transparent grey; Table S2), together with the individual data used for this calculation (see color code in the figure). The time evolutions of the mean declinations and inclinations, with their 95\%-confidence error bands, are also shown in Fig. S3. Schematically, the average curve can be described as follows: a first segment from the first century BC to the 6th century marked by a back and forth evolution of the inclinations (while the declinations remain fairly constant), a second segment marked by a broad, counterclockwise semicircle between $\sim 800$ and $\sim 1350 \mathrm{AD}$, and a third segment between 1400 and $1700 \mathrm{AD}$, in which the directions 
describe about one third of a clockwise circle, with a curvature similar to that of the previous segment. Note that between $\sim 1700$ and 2000 AD, it is well known that the geomagnetic directions described a tighter clockwise semicircle (double line in pale green, Fig. 10b and details in Table S4; Jackson et al., 2000; Le Goff and Gallet, 2017).

Over the two last millennia, three periods are marked by a clear change in the direction of geomagnetic drift: 150-350 AD, 600-800 AD and 1350-1400 AD. These changes were probably rapid, but the accuracy of the dating of the data remains insufficient (despite the selection criterion) for precisely defining the exact nature of these transitions. Apart from these transitions, the evolution of the mean archeomagnetic directions appears to be very regular, with only two slight inflections towards the 13th century and the middle of the 16th century. Here again, the limited accuracy of the dating of the available archeomagnetic data does not allow us to further discuss the origin of these inflections (Le Goff and Gallet, 2019). Finally, the 15th century seems to be marked by the most rapid directional variations, which are underlined by a very strong elongation of the 95\%-confidence ellipse of the mean direction, with $1450 \mathrm{AD}$ as the central date. Without challenging this observation, it should however be noted that this is the longest window duration (Fig. 10a) because data for the 15th century are still scarce (Fig. 6).

Figure 11 shows a comparison between the new DSV curve and the previous ones obtained by Bucur (1994) using sliding windows of fixed duration (80 years) and by Le Goff et al. (2002) using the same database but with sliding windows of various durations. (Note that in the latter study, the confidence ellipses were drawn by considering the weighted number of samples instead of the weighted number of archeomagnetic data available at the structure level, as used in Fig. 10b). Unsurprisingly, the curves are similar, and exactly the same patterns of variation can be observed. Overall, the new curve tends to smooth the rapid fluctuations that previously occurred from one window to the other. In addition, notable 
differences with now smaller inclinations highlight the period between $\sim 600$ and $~ 850$ AD. Paradoxically, however, it is difficult to know whether these differences correspond to a real improvement in our knowledge of the detailed directional variations, or whether this smoother evolution is rather the result of an increase in the number of data with levels of dating accuracy that are arguably insufficient to trace all the expected variability in the geomagnetic field (Le Goff and Gallet, 2019). Nevertheless, whichever option is chosen, the new DSV curve is more robust from a statistical point of view than the old one.

\subsection{Comparison of the revised French DSV curve with other Western European curves}

The new French DSV curve is compared in Fig. 12 with other regional curves established in neighbouring countries, namely Germany (Schnepp and Lanos, 2005), the UK (Batt et al., 2017) and Iberia (Molina-Cardín et al., 2018). The latter curves are based on databases that cover most of the last two millennia with only a weak influence of the French database (i.e. that of Bucur, 1994). In Fig. 12, these curves are presented as calculated by their authors, as it was not our objective to discuss the different techniques used to calculate them (see discussion in Schnepp and Lanos, 2005; Lanos et al., 2005; Lodge and Holme, 2009; Batt et al., 2017 and Molina-Cardín et al., 2018). Each curve is assumed to reproduce as closely as possible the regional directional variations and it is considered that no particular method of curve calculation can introduce erroneous segments of secular variation. The differences observed in Fig. 12 are therefore due to a potentially different geomagnetic field behavior between the regions considered and/or to differences in the temporal resolution between the different curves, given the different databases and the techniques used for their construction.

Overall, the curves show basically the same patterns of directional variations (Fig. 12). This is not surprising if we refer, for instance, to the historical period for which the direct 
directional measurements made in France and England over more than three centuries are exactly the same after a correction for latitude (e.g. Alexandrescu et al., 1997; see also Le Goff and Gallet, 2017). One can also consider the volcanic archeomagnetic data from Vesuvius and Etna (southern Italy) obtained by Tanguy et al. (2003; 2007; 2009), which show the same secular variation pattern as the French DSV. Reasonably, and in accordance with regional (e.g. Pavón-Carrasco et al. 2009) and global (e.g. Jackson et al., 2000; Licht et al., 2013; Nilsson et al., 2014; Arneitz et al., 2019) geomagnetic field reconstructions, the secular variation has likely remained fairly homogeneous on the Western European spatial scale over the last two millenia.

The differences observed should therefore primarily depend on the different characteristics of the databases (i.e., the number, accuracy and temporal distribution of the data; see also discussion in Le Goff and Gallet, 2019). From the corresponding databases, we extracted the 110 (Germany), 759 (UK) and 99 (Iberia) individual directional data (right-hand panels in Fig. 12). On average, the data from these three regions are more scattered than the French data, both at the individual data level (with higher $\alpha_{95}$ values) and collectively, at the level of all the data (compare with Fig. 10b). The uncertainties, shown as confidence circles, associated with the mean DSV curves are probably too optimistic, which is a recurrent problem in archeomagnetic field reconstructions (see for instance discussion in Korte et al., 2005; Korte and Constable, 2011); however, this is particularly critical for the UK curve (Fig. 12c,d). While all the other curves are only based on the corresponding regional database alone, the UK DSV curve is the result of an inversion of the global (worldwide) database, incorporating a significant overweighting of the data from the UK. However, there is a rather paradoxical situation pertaining to the UK curve marked by the absence of mean directions with high inclinations during the period from the $\sim 5$ th to the $\sim 8$ th centuries, which are, on the contrary, clearly included in the French and German DSV curves (Fig. 12e,f) and, to a lesser 
extent, in the Iberian curve (Fig. 12a,b). This seems to be mainly due to the paucity of archeomagnetic data in the UK during this specific time interval (see Fig. 5b in Batt et al., 2017), as well as their scatter, and this problem is not alleviated by the data available in neighbouring regions, contrary to what the method used by Batt et al. (2017) might suggest. The most critical aspect is that the low number of UK data from this period does not result in a significant (expected) increase in the uncertainties associated with the mean directions, which are therefore much too optimistic. In this respect, the angular uncertainties associated with the German DSV curve seem more realistic (Fig. 12a,b). The latter DSV curve does not show the directions with inclinations as low as $\sim 55^{\circ}$ between $\sim 1200 / 1300$ and $\sim 1400$ AD that are present in both the French and Iberian curves. However, it should be noted that such data are now present in the recently updated archeomagnetic database (Schnepp et al., 2020).

Figure 12 highlights, in a simple and very general way, the need to homogenize the methods used to estimate regional DSV curves. This is particularly necessary if the secular variation is to be studied on a spatial scale such as that of Europe without resorting to a more global reconstruction of the geomagnetic field, the resolution of which is still limited, or if the significance of the archeomagnetic data obtained from different regions is to be analyzed (i.e., in order to establish a coherent archeological scheme on a scale beyond the framework of a single country). Concerning this last point, it should finally be remembered that the approach developed by Le Goff et al. (2002) is particularly well adapted to the use of the DSV curve for archeomagnetic dating purposes (see also the Bayesian approach developed by Lanos, 2004).

\section{Concluding remarks}


This study summarized 25 years of research in archeomagnetism carried out in the

laboratory created by Emile Thellier. It completes the work of Ileana Bucur with the construction of a new reference curve of the directional variations in the geomagnetic field in France over the last two millennia. It also concludes more than 80 years of research in archeomagnetism carried out at the Saint-Maur Observatory (created in 1880 by Eleuthère Mascart), at a time when the laboratory for the analysis of archeomagnetic directions has just been installed at Chambon-la-Forêt within the French National Magnetic Observatory.

Note that the programs allowing the calculation of a DSV curve and its use for archeomagnetic dating using the method developed by Le Goff et al. (2002) are available upon request.

\section{Acknowledgments}

This study is dedicated to the memory of Emile Thellier, who, a long time ago now, committed MLG to the path of paleo-archeomagnetism research. We are grateful to Ileana Bucur who introduced YG and AG to archeomagnetism. We also thank Jean-Claude Tanguy who, at the same time as this study was being performed, doggedly worked on the archeomagnetism of his beloved Italian volcanoes. We are grateful to Laurent Boissin, Gaétan Gouérou, Lucie Garnier and Aurélia Alligri who carried out some of the archeomagnetic measurements, and all the archeologists who made this study possible. Finally we would like to thank two anonymous reviewers who made useful comments on the manuscript. This work was partly supported by the Fondation Simone and Cino Del Duca of Institut de France (2017 Research Grant). IPGP contribution no. 4166. 


\section{References}

Aitken, M. J., Hawley, H. N., 1971. Archaeomagnetism: evidence for magnetic refraction in kiln structures. Archaeometry 13, 83-85.

Alexandrescu, M., Courtillot, V., Le Mouël, J.-L., 1997. High-resolution secular variation of the geomagnetic field in western Europe over the last 4 centuries: comparison and integration of historical data from Paris and London. J Geophys Res 102(B9), 2024520258

Arneitz, P., Egli, R., Leonhardt, R., Fabian, K., 2019. A Bayesian iterative geomagnetic model with universal data input: Self-consistent spherical harmonic evolution for the geomagnetic field over the last 4000 years. Phys. Earth planet. Inter. 290, 57-75.

Batt, C.M., Brown, M.C., Clelland, S.-J., Korte, M., Linford, P., Outram, Z., 2017. Advances in archaeomagnetic dating in Britain: New data, new approaches and a new calibration curve. J. Archaeolog. Sci. 85, 66-82.

Bucur, I., 1994. The direction of the terrestrial magnetic field in France during the last 21 centuries. Phys. Earth Planet. Inter. 87, 95-109.

Brown, M. C., Donadini, F., Korte, M., Nilsson, A., Korhonen, K., Lodge, A., Lengyel S.N., Constable, C. G., 2015. GEOMAGIA50.v3: 1. general structure and modifications to the archeological and volcanic database. Earth Planets Space 67, 83.

Chauvin, A., Garcia, Y., Lanos, P., Laubenheimer, F., 2000. Paleointensity of the geomagnetic field recovered on archaeomagnetic sites from France. Phys. Earth Planet. Inter. 120, 111-136.

Constable, C., Korte, M., Panovska, S., 2016. Persistent high paleosecular variation activity in southern hemisphere for at least 10000 years. Earth Planet. Sci. Lett. 453, 78-86. 
Desrayaud, G., 2010. Saint-Pathus (Seine-et-Marne), Le Bois de l'Homme Mort: établissements ruraux antiques et petit temple gallo-romain (fanum) du «Bois de l'Homme Mort » : milieu II ${ }^{e}$ s. avant - début Ve s. après J.-C.. Inrap (Centre Île-deFrance) excavation report, 1 vol. (461 pp.), available at dolia.inrap.fr.

Dunlop, D, Ozdemir, O, 1997. Rock magnetism, Fundamental and Frontiers. Cambridge Univ. Press, 573 pp.

Evans, M.E., Hoye, G.S., 2005. Archaeomagnetic results from southern Italy and their bearing on geomagnetic secular variation. Phys. Earth Planet. Inter. 151, 155-162.

Gallet, Y., Genevey, A., Le Goff, M., 2002. Three millennia of directional variation of the Earth's magnetic field in western Europe as revealed by archeological artifacts. Phys. Earth. Planet. Inter. 131, 81-89.

Genevey, A., Gallet, Y., 2002. Intensity of the geomagnetic field in western Europe over the past 2000 years: New data from ancient French pottery. J. Geophys. Res. 107, No. B11, 2285.

Genevey, A., Gallet, Y., Constable, C. G., Korte, M., Hulot, G., 2008. ArcheoInt: An upgraded compilation of geomagnetic field intensity data for the past ten millennia and its application to the recovery of the past dipole moment. Geochem. Geophys. Geosyst. 9, Q04038.

Genevey, A., Gallet, Y., Rosen, J., Le Goff, M., 2009. Evidence for rapid geomagnetic field intensity variations in Western Europe over the past 800 years from new archeointensity French data. Earth Planet. Sci. Lett. 284, 132-143.

Genevey, A., Gallet, Y., Thébault, E., Jesset, S., Le Goff, M., 2013. Geomagnetic field intensity variations in Western Europe over the past 1100 years. Geochem. Geophys. Geosyst. 14/8, 2858-2872. 
Genevey, A., Gallet, Y., Jesset, S., Thébault, E., Bouillon, J., Lefèvre, A., Le Goff, M., 2016. New archeointensity data from French Early Medieval ceramic production (6th-10th century AD). Tracing 1500 years of geomagnetic field intensity variations in Western Europe. Phys. Earth Planet. Inter. 257, 205-219.

Gentili, F., 2000. Villiers-le-Sec (Val d’Oise), La Place de la Ville, document final de synthèse. Afan, Saint-Ouen-l’Aumône, Service Départemental d'Archéologie du Val d’Oise, Saint-Denis, Service Régional de l’Archéologie Île-de-France, 3 vol. (142, 424, 721 pp.), available at dolia.inrap.fr.

Gómez-Paccard, M., Chauvin, A., Lanos, P., McIntosh, G., Osete, M., Catanzariti, G., RuizMartinez, V., Nunez, J.I., 2006. The first secular variation curve for the Iberian peninsula. Comparison with other data from Western Europe and with geomagnetic global field models. Geochem. Geophys. Geosys 7(12) Q12001.

Hellio , G., Gillet, N., 2018. Time-correlation-based regression of the geomagnetic field from archeological and sediment records. Geophys. J. Int. 214, 1585-1607.

Hervé, G., Chauvin, A., Lanos, P., 2013a. Geomagnetic field variations in Western Europe from 1500 BC to 200 AD. Part I: directional secular variation curve. Phys. Earth Planet. Inter. 218, 1-13.

Hervé, G., Chauvin, A., Lanos, P., 2013b. Geomagnetic field variations in Western Europe from 1500 BC to 200 AD. Part II: New intensity secular variation curve. Phys. Earth Planet. Inter., 218, 51-65

Hongre, L., Hulot, G., Khokhlov, A., 1998. An analysis of the geomagnetic field over the past 2000 years. Phys. Earth Planet. Inter. 106, 311-335.

Hurard, S., 2011. Saint-Pathus (Seine-et-Marne), Les Petits Ormes : longue durée d’occupation du Néolithique à l'époque moderne : mutations d’un habitat rural du Bas- 
Empire à la fin du premier Moyen Âge. Inrap (Centre Île-de-France) excavation report, 4 vol. (346, 474, 154, 923 pp.), available at dolia.inrap.fr.

Jackson, A., Jonkers, A.R.T., Walker, M.R., 2000. Four centuries of geomagnetic secular variation from historical records, Phil. Trans. R. Soc. Lond. A358, 957-990.

Jego, L., 2010. Un « lotissement» gaulois sous le green... Evreux (Eure). Inrap (Grand Ouest) excavation report, 1 vol. (273 pp.), available at dolia.inrap.fr.

Korte, M., Genevey, A., Constable, C.G., Frank, U., Schnepp, E., 2005. Continuous geomagnetic field models for the past 7 millennia: 1. A new global data compilation. Geochem. Geophys. Geosyst. 6 (2), Q02H15.

Korte, M., Constable, C.G., 2005. Continuous geomagnetic field models for the past 7 millennia II: CALS7K. Geochem. Geophys. Geosys. 6(2) Q02H16.

Korte, M., Constable, C., 2011. Improving geomagnetic field reconstructions for 0-3 ka. Phys. Earth Planet. Inter. 188 (3-4), 247-259.

Kovacheva, M., Chauvin, A., Jordanova, N., Lanos, P., Karloukovski, V., 2009. Remanence anisotropy effect on the palaeointensity results obtained from various archaeological materials, excluding pottery, Earth Planets Space, 61, 711-732.

Lanos, P., 1987. The effects of demagnetizing fields on thermoremanent magnetization acquired by parallel-sided baked clay blocks. Geophys J. R. astr. Soc. 91, 985-1012.

Lanos, P., 2004. Bayesian inference of calibration curves: application to archaeomagnetism. in Tools for constructing chronologies: crossing disciplinary boundaries, C. Buck and A. Millard Eds. Springer-Verlag, London vol. 17, 43-82.

Lanos, P., Le Goff, M., Kovacheva, M., Schnepp, E., 2005. Hierarchical modelling of archaeomagnetic data and curve estimation by moving average technique Geophys. J. 
Le Goff, M., 1975. Inductomètre à rotation rapide continue pour la mesure des faibles aimantations rémanentes et induites en magnétisme des roches. Mém. Diplôme d’Ingénieur CNAM Paris, 85 pp.

Le Goff, M., 1990. Lissage et limites d'incertitude des courbes de migration polaire: pondération des données et extension bivariante de la statistique de Fisher. C. R. Acad. Sci. Sér. II 311, 1191-1198.

Le Goff, M., Henry, B., Daly, L., 1992. Practical method for drawing a VGP path. Phys. Earth Planet. Int. 70, 201-204.

Le Goff, M., Gallet, Y., Genevey, A., Warmé, N., 2002. On archaeomagnetic secular variation curves and archaeomagnetic dating. Phys. Earth Planet. Inter. 134, 203-211.

Le Goff, M., Gallet, Y., 2017. A reappraisal of instrumental magnetic measurements made in Western Europe before AD 1750: confronting historical geomagnetism and archaeomagnetism. Earth Planets and Space 69, 32.

Le Goff, M., Gallet, Y., 2019. On the resolution of regional archaeomagnetism: untangling directional geomagnetic oscillations and data uncertainties using the French archaeomagnetic database for dates between AD 1000 and 1500 as a guide. Geological Society, London, Special Publications, 497.

Licht, A., Hulot, G., Gallet, Y., Thébault, E., 2013. Ensembles of low degree archeomagnetic field models for the past three millennia. Phys. Earth. Planet. Inter., 224, 38-67.

Lodge, A., Holme, R., 2009. Towards a new approach to archaeomagnetic dating in Europe using geomagnetic field modelling. Archaeometry 51, 309-322. 
Martón, P., Ferencz, E., 2006. Hierarchical versus stratification statistical analysis of archaeomagnetic directions: the secular variation curve for Hungary. Geophys. J. Int. 164, 484-489.

McFadden, P., McElhinny, M., 1990. Classification of the reversal test in palaeomagnetism. Geophys. J. Int. 103, 725-729

Molina-Cardín, A., Campuzano, S. A., Osete, M. L., Rivero-Montero, M., Pavón-Carrasco, F. J., Palencia-Ortas, A., Martín-Hernández, F., Gómez-Paccard, M., Chauvin, A., Guerrero-Suárez, S., Pérez-Fuentes, J. C., McIntosh, G., Catanzariti, G., Sastre Blanco, J. C., Larrazabal, J., Fernández Martínez, V. M., Álvarez Sanchís, J. R., RodríguezHernández, J., Martín Viso, I., Garcia i Rubert, D., 2018. Updated Iberian Archeomagnetic Catalogue: New Full Vector Paleosecular Variation Curve for the Last Three Millennia. Geochem. Geophys. Geosyst. 19, 10, 3637-3656.

Nilsson, A., Holme, R., Korte, M., Suttie, N., Hill, M., 2014. Reconstructing Holocene geomagnetic field variation: new methods, models and implications. Geophys. J. Int. 198, 229-248.

Pavón-Carrasco, F. J., Osete, M. L., Torta, J. M., Gaya-Pique, L. R., 2009. A regional archeomagnetic model for Europe for the last 3000 years, SCHA.DIF.3K: Applications to archeomagnetic dating, Geochem. Geophys. Geosyst. 10, Q03013.

Pavón-Carrasco, F. J., Rodríguez-González, J., Osete, M. L., Torta, J. M., 2011. A matlab tool for archeomagnetic dating. J. Archeol. Sci. 38 (2), 408-419.

Pavón-Carrasco, F. J., Osete, M. L., Torta, J. M. \& De Santis, A., 2014. A geomagnetic field model for the Holocene based on archeomagnetic and lava flow data. Earth Planet. Sci. Lett. 388, 98-109. 
Rouzeau, B., Genevey, A., Gallet, Y., Le Goff, M., 2015. New constraints on the metallurgical activity at the Morimond Abbey (Haute-Marne) from the archeomagnetic analysis of two excavated brick fireplaces. ArcheoSciences, revue d'archéométrie 39, 39-49.

Sanchez, S., Fournier, A., Aubert, J., Cosme, E., Gallet, Y., 2016. Modelling the archaeomagnetic field under spatial constraints from dynamo simulations: A resolution analysis. Geophys. J. Int. 207, 983-1002.

Schnepp, E., Lanos, P., 2005. Archaeomagnetic secular variation in Germany during the past 2500 years. Geophys. J. Int. 163, 479-490.

Schnepp, E., Thallner, D., Arneitz, P., Mauritsch, H., Scholger, R., Rolf, C., Leonhardt, R., 2020. New archaeomagnetic secular variation data from Central Europe. I: Directions. Geophys. J. Int. 220, 1023-1044.

Schurr, K., Becker, H., Soffel, H. C., 1984. Archaeomagnetic study of medieval fireplaces at mannheim-Waldstadt and ovens from Herrenchiemsee (southern Germany) and the problem of magnetic refraction. J. Geophys. 56, 1-8.

Shaar, R., Hassul, E., Raphael, K., Ebert, Y., Segal, Y., Eden, I., Vaknin, Y., Marco, S., Nowaczyk, N. R., Chauvin, A., Agnon, A., 2018. The first catalog of archaeomagnetic directions from Israel with 4,000 years of geomagnetic secular variations. Front. Earth Sci. 6, 164.

Soffel, H. C., Schurr, K., 1990. Magnetic refraction studied on two experimental kilns. Geophys. J. Int. 102, 551-562.

Tanguy, J.C., LeGoff, M., Principe, C., Arrighi, S., Chillemi, V., Paiotti, A., LaDelfa, S., Patanè, G., 2003. Archeomagnetic dating of Mediterranean volcanics of the last 2100 years: validity and limits. Earth Planet. Sci. Lett. 211, 111-124. 
Tanguy, J.-C., Condomine, M. Le Goff, M., Chillemi, V., La Delfa, S., Patanè, G., 2007. Mount Etna eruptions of the last 2,750 years: revised chronology and location through archeomagnetic and ${ }^{226} \mathrm{Ra}^{230}$ Th dating. Bull. Volcano. 70, 55-83.

Tanguy, J.-C., Le Goff, M., Arrighi, S., Principe, C., Ladelfa, S., Patanè, G., 2009. The history of Italian volcanoes revised by archeomagnetism. EOS 90 (40), 349-350.

Tanguy, J.-C., Bachélery, P., Le Goff, M., 2011. Archeomagnetism of Piton de la Fournaise: Bearing on volcanic activity at La Réunion Island and geomagnetic secular variation in Southern Indian Ocean. Earth Planet. Sci. Lett. 303, 361-368.

Tarling, D. H., Dobson, M. J., 1995. Archaeomagnetism: An error assessment of fired material observations in the British directional database. J. Geomag. Geoelectr. 47, 518.

Tarling, D. H., 1999. The global archaeomagnetic database. Geophys. Res. Abstr. 1, 161.

Tema, E., Ferrara, E., Angelici, D., Fantino, F., Panero, E.,. 2019. The importance of multidisciplinary dating in rescue excavations: The case of Santhià, Northern Italy. J. Archeol. Sci.: Reports 28, 102059.

Tema, E., Hedley, I., Lanos, P., 2006. Archeomagnetism in Italy: a compilation of data including new results and a preliminary Italian secular variation curve. Geophys. J. Int. 167, 1160-1171.

Thellier, E., 1938. Sur l'aimantation des terres cuites et ses applications géophysiques. Ann. Inst. Phys. Globe Univ. Paris 16, 157-302.

Thellier, E., 1967a. Methods of sample collection and orientation for Archaeomagnetism. Methods in Palaeomagnetism, Elsevier Amsterdam, 16-21. 
Thellier, E., 1967b. A big sample spinner magnetometer. In Methods in Palaeomagnetism, Elsevier Amsterdam, 149-154.

Thellier, E., 1981. Sur la direction du champ magnétique terrestre en France durant les deux derniers millénaires. Phys. Earth Planet. Inter. 24, 89-132. 


\section{Figure captions}

Fig. 1. Location map (Mercator projection) of the archeomagnetic data obtained in metropolitan France. The surface of France was divided into rectangles of $0.5^{\circ}$ longitude by $0.25^{\circ}$ latitude ( $40 \mathrm{~km}$ by $28 \mathrm{~km}$ ), in which the number of available data is indicated. The map also shows the contours of the Ile-de-France region (blue line), where most of the new results were obtained. The yellow star indicates the location of Paris.

Fig. 2. Different stages of sample collection and preparation in the laboratory (following Thellier, 1938; 1967b). (a) Isolation of large blocks on the floor of a kiln, and their embedding with plaster strips. (b) Moulding of horizontal plaster caps on top of the blocks, on which orientation with respect to the (c) geomagnetic north and (d) sun direction are recorded. (e) Preparation of samples in the laboratory with standardization of the sample size using 12cm cubic moulds. (f) Inductometer used in the laboratory to measure the magnetization of large samples (Le Goff, 1975).

Fig. 3. Determination of VRM and TRM direction from six kilns of different ages, with an averaged viscosity index $v_{\text {mean }}$ ranging from $13.8 \%$ to $0.9 \%$. The different panels are screenshots of the measurement program used in the laboratory, showing on a Cartesian (D,I) diagram the directions deduced after the viscosity test and reduction to Paris. The red crosses indicate the TRM directions obtained from each sample (the circled one is being processed). The black crosses display the VRM directions obtained for the different samples. The yellow circle shows the present-day field direction in the laboratory.

Fig. 4. (a),(b) Comparison between the TRM directions from the Thellier method and the results for the same samples derived from AF demagnetization up to $30 \mathrm{mT}$ and $20 \mathrm{mT}$ (kiln studied in Tremblay and Varennes, respectively). In these orthogonal diagrams, each small colored symbol shows the demagnetization data obtained for a sample (with data from 11 
samples in (a) and 4 samples in (b)). The big open symbols and the associated thick lines display the TRM direction obtained using the Thellier protocol after direct and reverse viscosity experiments, while the yellow dots show the resulting $\mathrm{TRM}_{\mathrm{Th}}$ directions. The yellow arrows in (b) highlight the viscous effet due to a time lag between the two series of measurements. While AF demagnetization is necessary to remove this effet, the dotted lines illustrate the fact that it is well taken into account by the Thellier protocol. (c) Comparison between the mean TRM directions obtained by the Thellier method (95\%-confidence ellipses in lilac; measurements carried out by Thellier in 1972) and the classical paleomagnetic methodology involving thermal demagnetization and TRM anisotropy correction (95\%confidence ellipses in yellow; P. Lanos and J. Thiriot, pers. comm., 2011) obtained from six different kilns (three for each procedure) sampled at Saint-Gilles-du-Gard in 1972 and 2007 respectively, and assumed to be of the same age. The contour of the 95\%-confidence ellipses of the two general mean directions are shown with dotted lines. The thick line in grey and red is the DSV curves estimated in this study.

Fig. 5. (a) Histogram of the structure-averaged viscosity indices of all results obtained using the Thellier's protocol. In green, all the data considered in the French database (Table S1); in white, only the data with dating uncertainties $\leq 50$ years. The magenta bars show both the data eliminated because their viscosity index is too high $(>12 \%)$ and the so-called abnormal (VA) values reported by Bucur (1994) to which we have added six new data because their directions deviate significantly from the age corresponding segments of the mean DSV curve that we calculate (Fig. 10; Table S2). Note that data with viscosity indices $>12 \%$ are reported only to illustrate the fact that their number is small in relation to the total number of structures analyzed. (b) Histogram of the 95\%-confidence circles $\left(\alpha_{95}\right)$. In blue, all data ; in white, the data with dating uncertainties of $\leq 50$ years. 
Fig. 6. Age distribution of the data considered in this study. (a) Age distribution of 170 directions from the Thellier-Bucur database (Thellier, 1981; Bucur, 1994). (b) Age distribution of the 528 results obtained in our laboratory over the past 25 years. (c) Age distribution of 286 data from the two previous datasets, with dating uncertainties of $\leq 50$ years.

Fig. 7. Spherical projections of the available archeomagnetic directions. (a) All data with a color code depending of their $\alpha_{95}$ values (see text and code on the figure). (b) Available directions dated between $100 \mathrm{BC}$ and $1000 \mathrm{AD}$. The $\alpha_{95}$ circles are colored according to the central dates, with a color gradation as a function of the date uncertainties (see color code on the figure). Note that for the few data with $\alpha_{95}$ values $>2.6^{\circ}$, the colors are displayed with transparency (pale colors) to ease the reading. (c) Same as in (b), but for the data available between 1000 and 1900 AD. (d-f) Same as in (a-c), respectively, but only for the data with dating uncertainties of $\leq 50$ years.

Fig. 8. Spherical projection of the archeomagnetic directions obtained from three different archeomagnetic sites: (a) Saint Pathus, (b) Villiers le Sec, and (c) Evreux. The color code is a function of the $\alpha_{95}$ values (see code on the different panels). The thick line in grey and red is the DSV curves estimated in this study (see text) and the double pale green line is the DSV curve over the historical period determined between 1555 and 1750 by Le Goff and Gallet (2017) and from the gufm1 model (Jackson et al., 2000) after 1750 (Table S4).

Fig. 9. Spherical projection of the archeomagnetic directions with central dates between 450 and $750 \mathrm{AD}(\mathrm{a}, \mathrm{b})$ (i.e. during the Merovingian period), and between 1000 and $1300 \mathrm{AD}(\mathrm{c}, \mathrm{d})$ (i.e. during the Middle Ages period). The $\alpha_{95}$ circles are colored according to the dating uncertainties of the corresponding data (see code in the different panels). (a,c) All data, (b,d) Only data with dating uncertainties of $\leq 50$ years. See legend of Fig. 8 for the two curves in grey and red, and in pale green. 
Fig. 10. The new DSV curve for France for the last two millennia. Only data with an age uncertainty of $\leq 50$ years were used after their transfer to the Paris coordinates $\left(48.9^{\circ} \mathrm{N}\right.$, $2.3^{\circ} \mathrm{E}$ ) (see text). The DSV curve was constructed using the method developed by Le Goff et al. (2002). (a) Statistical weights (in black, left graduation) and half durations (in blue, right graduation) of the different time windows isolated over the last two millennia. (b) Spherical projection of the mean archeomagnetic directions calculated between the first century BC and 1700 AD (red-white curve) with the corresponding 95\%-confidence ellipses (in transparent grey). The individual archeomagnetic data used for these calculations are also shown with their 95\%-confidence circles colored according to their values (see code in the figure). A few individual archeomagnetic data younger than 1700 are also shown in pale colors. The double curve in pale green illustrates the evolution of the geomagnetic directions provided by instrumental measurements (Le Goff and Gallet, 2017; Jackson et al., 2000).

Fig. 11. Comparison of the new mean DSV curve calculated in this study (red-white line) with that calculated using the same method but with the Bucur (1994) database (green-white line; Le Goff et al., 2002) and that of Bucur (1994) using sliding windows of fixed duration (blue-grey line).

Fig. 12. Comparison of the new French DSV curve (red-white curve) with those previously proposed for Germany (a,b) (blue-white curve, from Schnepp and Lanos, 2005), the UK (c,d) (purple-white curve, from Batt et al., 2017) and Iberia (e,f) (green-white curve, from MolinaCardin et al., 2018). All directions have been transferred to the Paris coordinates. Details of the methods used for the construction of the latter curves are provided in the corresponding articles. The left-hand panels show the average curves, while the right-hand panels show the average curves for Germany (b), the UK (d) and Iberia (f), together with the individual archeomagnetic data used to construct the curves in question (see text). In the latter plots, the confidence circles for the reference curves are shown in transparent grey for every 50 years 
recovered from the tables provided by the authors. The 95\%-confidence circles of the individual data are shown with the same color code as in Fig. 10b, but also with empty circles for $\alpha_{95}>5.0^{\circ}$.

\section{Supplementary material}

Fig. S1. (a) $\alpha_{95}$ values for all directions obtained at the structure level, reported as a function of the number of results per structure (red diamonds, scaling to the left) and a histogram of the number of results per structure (in green, scaling to the right). (b) Histogram of the dating uncertainties of all available archeomagnetic directions.

Fig. S2. Time distribution of all declination (a, red dots) and inclination (b, blue dots) data before a selection based on their dating uncertainties (see text).

Fig. S3. Time evolution of the mean declinations and inclinations from the new French DSV curve (red and blue continuous lines, respectively), as interpolated from 10 year intervals in Table S3 . In both cases, the grey band shows the associated $\alpha_{95}$ Fisher confidence circles. The declinations and inclinations of the individual archeomagnetic data (i.e., obtained at the structure level) are also reported using red and blue dots, respectively. The curve segments in magenta (declinations) and cyan (inclinations) covering the past few centuries are constructed using direct magnetic measurements (Table S4).

Table S1. Mean TRM archeomagnetic directions from the Saint-Maur database including the results obtained by Thellier (1981), Bucur (1994) and this study. The first two datasets are in italics. Structure number: archeomagnetic data reference number (0-200, from Thellier, 1981; 300-399, from Bucur, 1994; from 400 and above, this study). \# indicates that either the dating or the grouping of data has been changed from the original publication. Structure Name: name of the archeological structure studied. Ref.: number associated with an archeological reference 
given in Text S1. * indicates that the archeological information was provided in Bucur (1994). Long. Site $\left({ }^{\circ}\right)$, Lat. Site $\left(^{\circ}\right)$ : location (longitude and latitude) of the structure. Decl. Site $\left(^{\circ}\right)$, Incl. Site $\left({ }^{\circ}\right)$ : declination and inclination of the TRM mean directions at the site locations. Decl. Paris $\left({ }^{\circ}\right)$, Incl. Paris $\left({ }^{\circ}\right)$ : declination and inclination of the TRM mean directions after transfer to the Paris coordinates. Nb: number of samples used for the determination of the TRM mean directions. $K, \alpha_{95}$ : Fisher parameter and radius of the 95\%-confidence circle of the TRM mean directions. v\%: structure-averaged magnetic viscosity index of the corresponding mean TRM directions. Central Date and $\Delta$ Date: central date and dating uncertainties of the structures. Type Structure: use of kilns. Note that the results in bold were used to estimate the French DSV master curve (see text).

Table S2. Archeomagnetic mean directions estimated in France since the first century BC according to the method developed by Le Goff et al. (2002). Date, Half Duration window: central date and half duration of the windows. Nb and Weighted results sum: raw number and weighted number of individual mean directions per window. Weighted samples sum: weighted number of directions at the sample level available for each time window. Decl. Paris $\left({ }^{\circ}\right)$, Incl. Paris $\left(^{\circ}\right)$ : declination and inclination of the mean direction estimated in Paris for each time window. $\Omega\left({ }^{\circ}\right)$ : elongation direction of the confidence ellipse of each mean direction. kx,ky: bivariate dispersion parameters. Fisher’s K: Fisher’s parameter of the mean direction estimated for each time window.

Table S3. Interpolation each 10 years of the mean DSV curve detailed in Table S2 (and see text). Same legend as in Table S2. In addition, the corresponding $\quad \alpha_{95}$ values are provided in the last column.

Table S4. Historical (direct) DSV curve in Paris determined between 1555 and 1750 by Le Goff and Gallet (2017) and from the gufm1 model (Jackson et al., 2000) after 1750. 
851 Text S1. List of known archeological references associated with the archeomagnetic data 852 detailed in Table S1. Each reference has a number that can be found in the third column of 853 Table S1. All these references are available at dolia.inrap.fr. * indicates that the archeological 854 information was provided in Bucur (1994). 


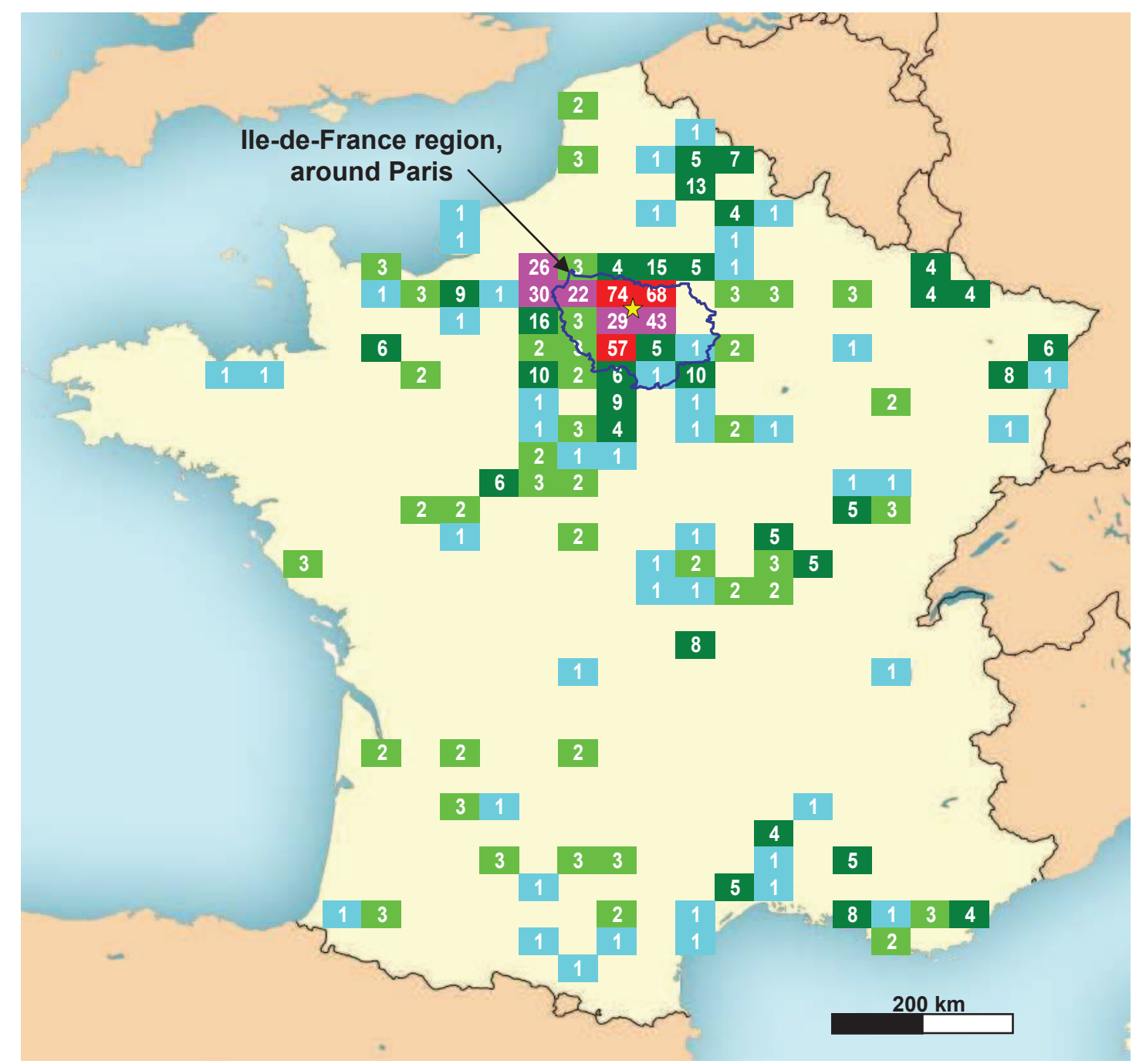

Figure 1 

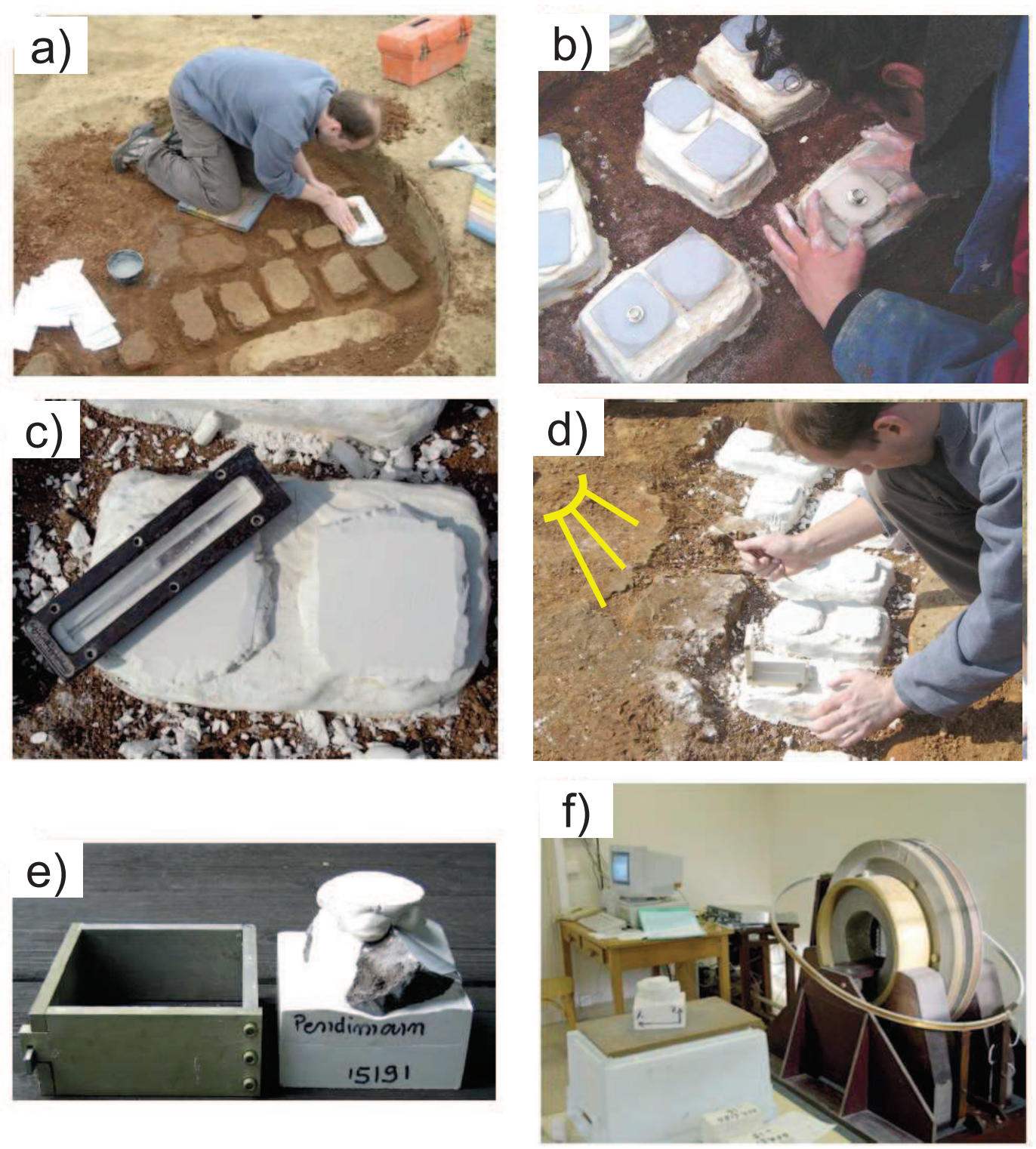

Figure 2 

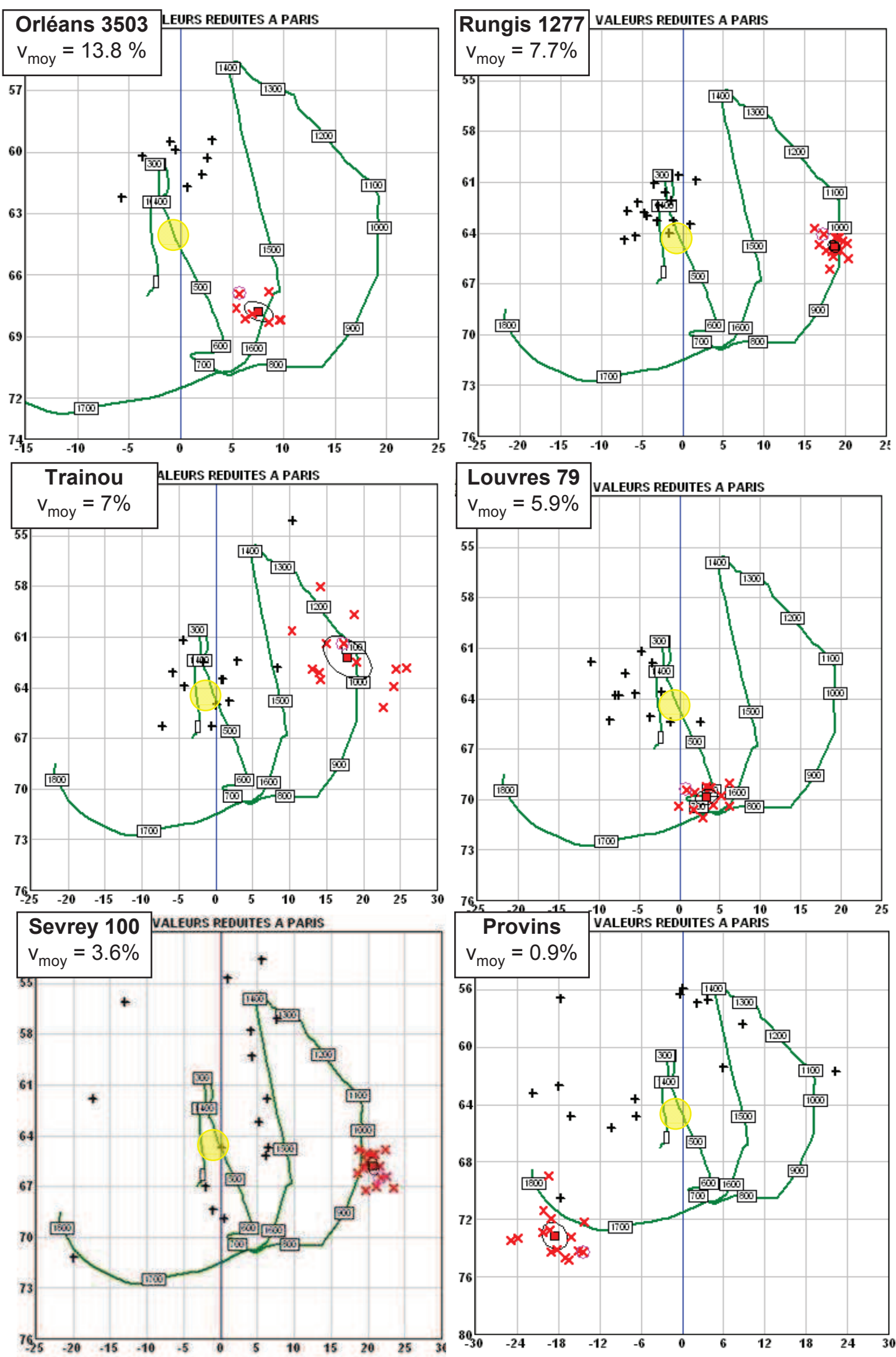

Figure 3 

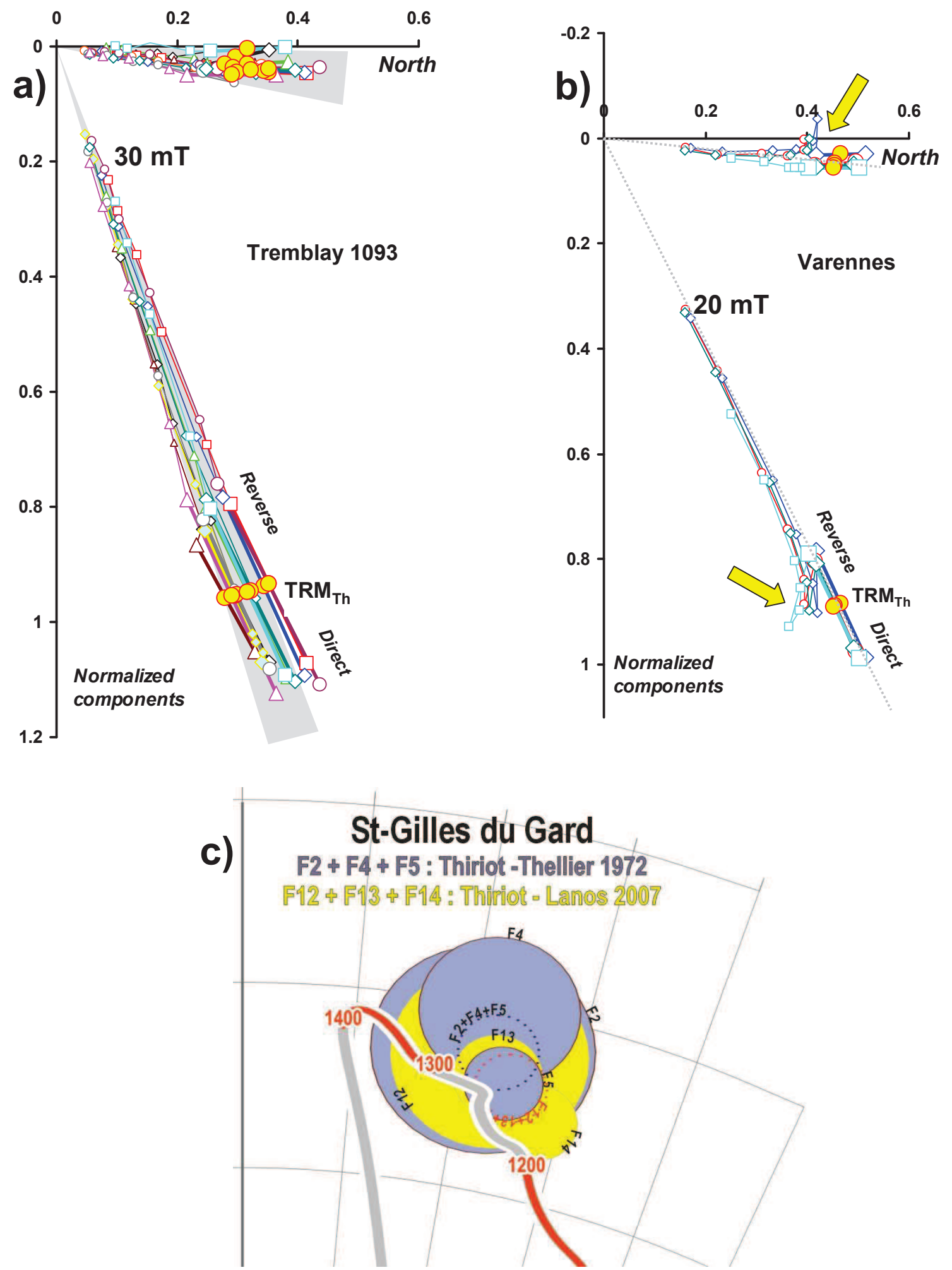

Figure 4 

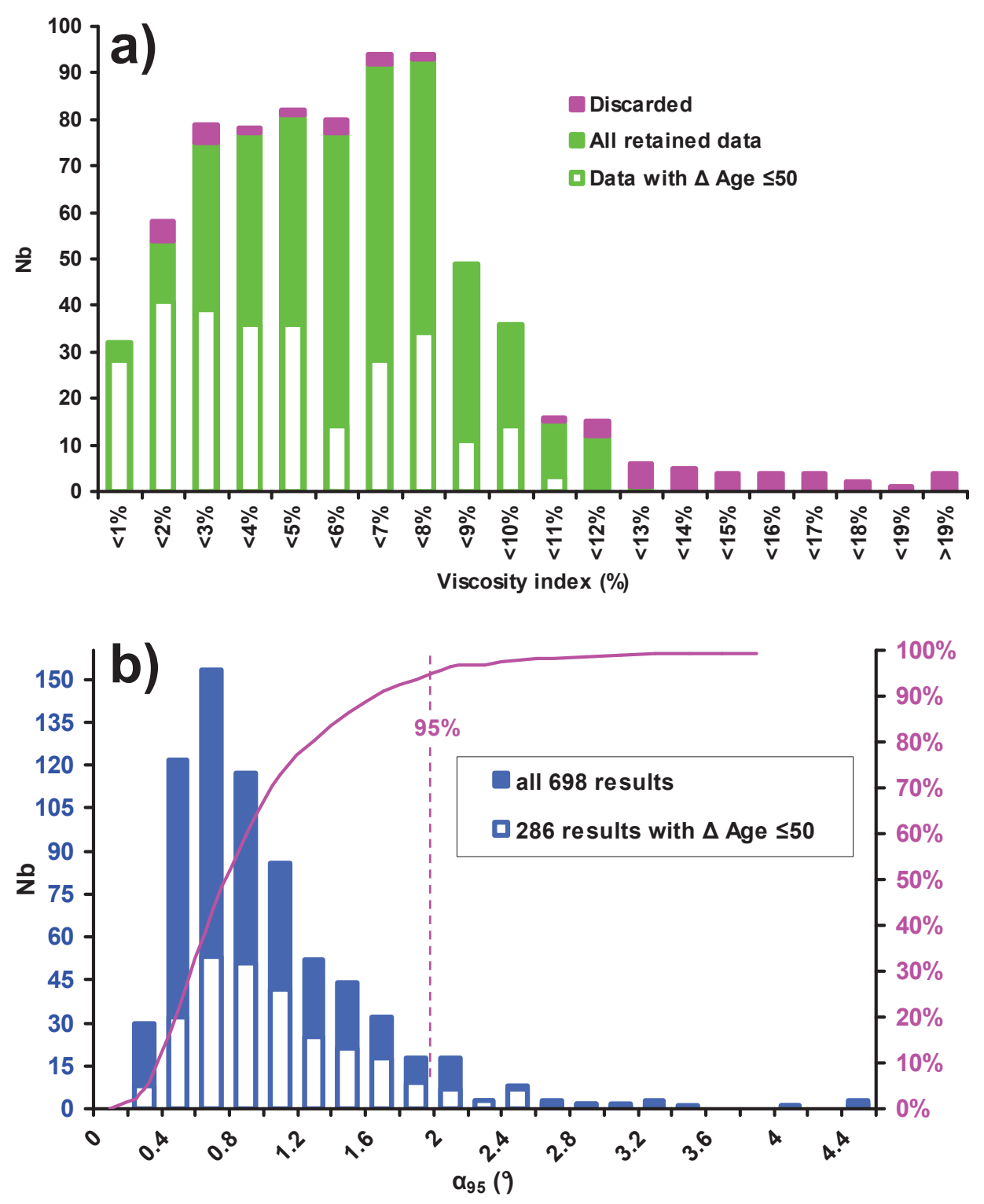

Figure 5 

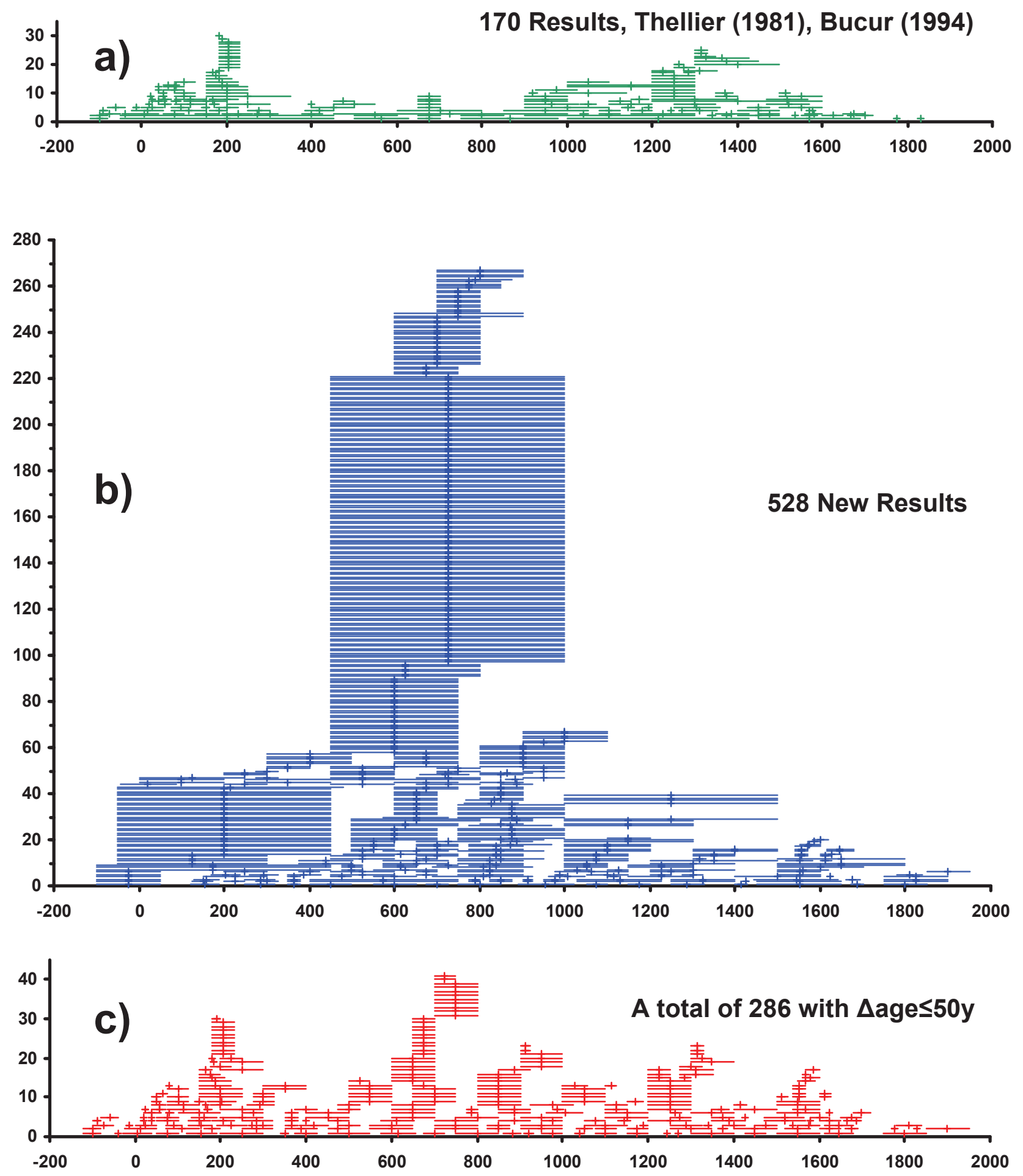

Figure 6 

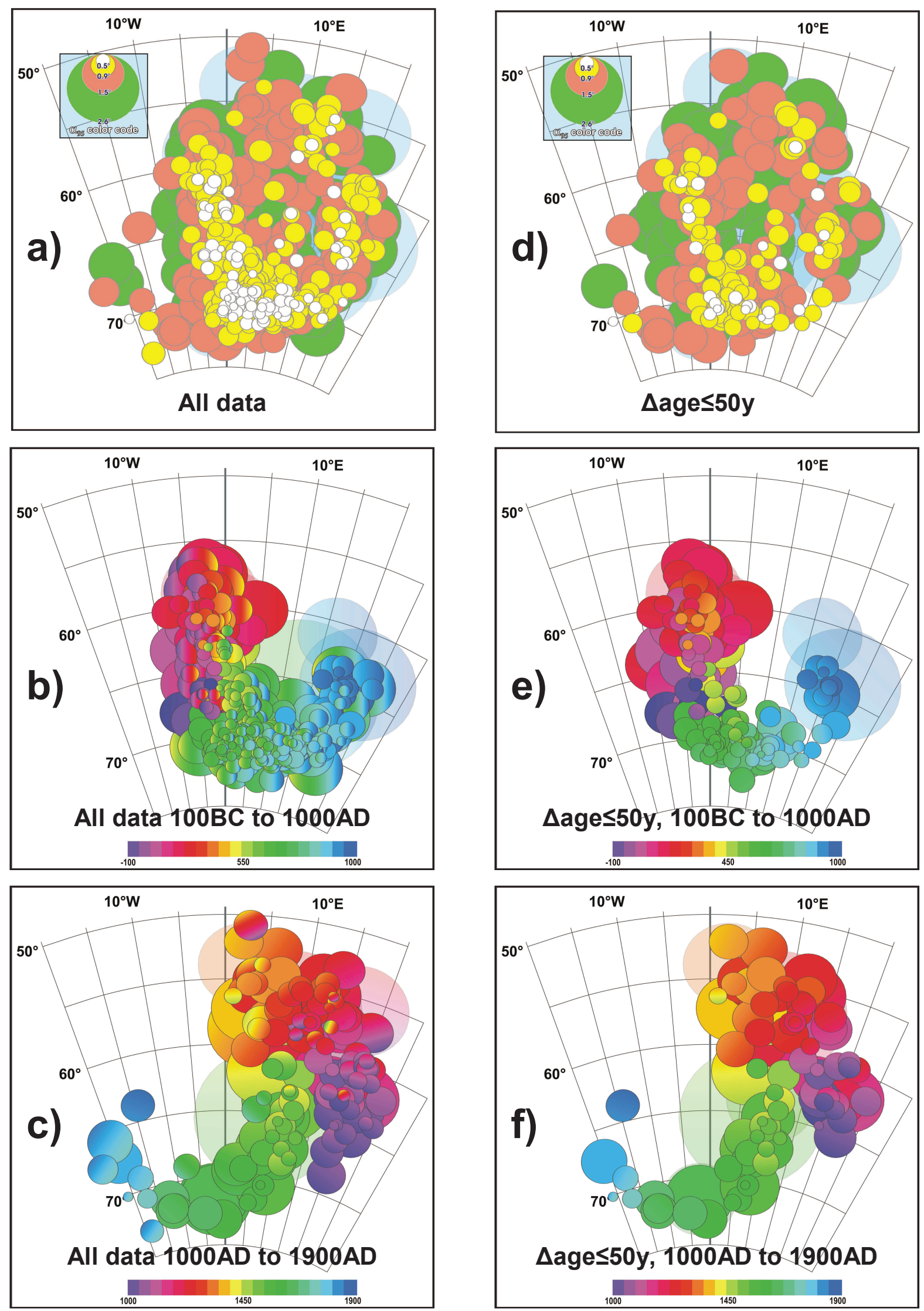

Figure 7 


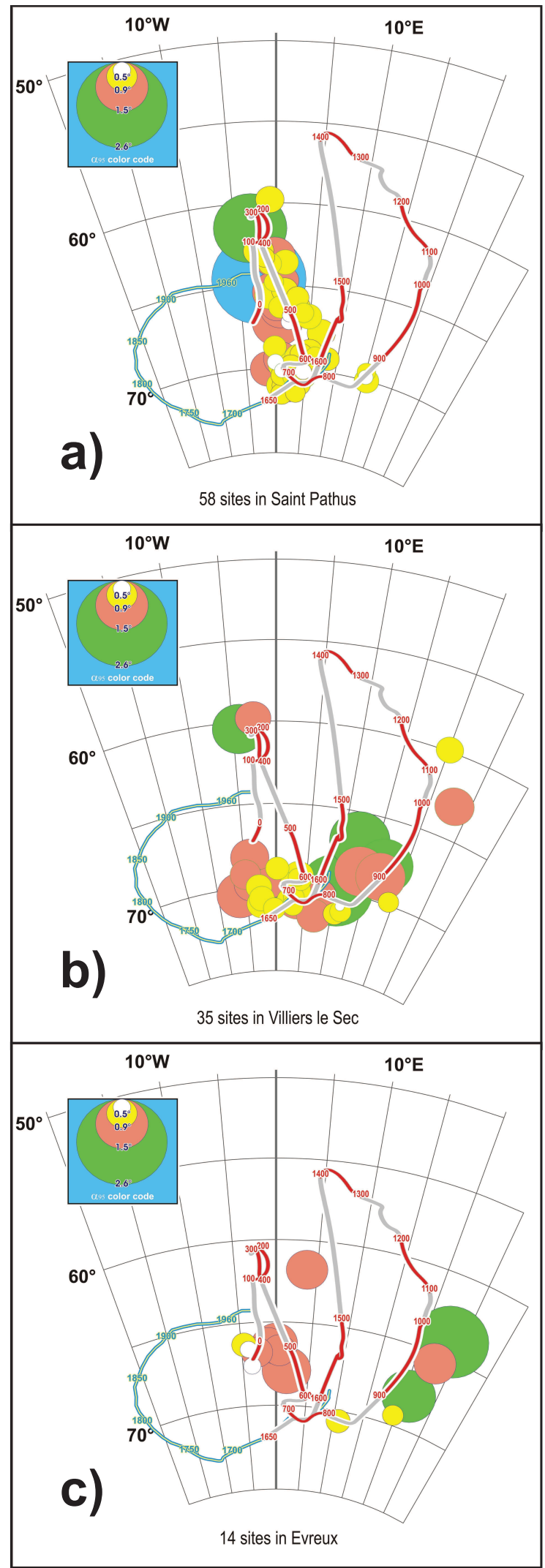

Figure 8 

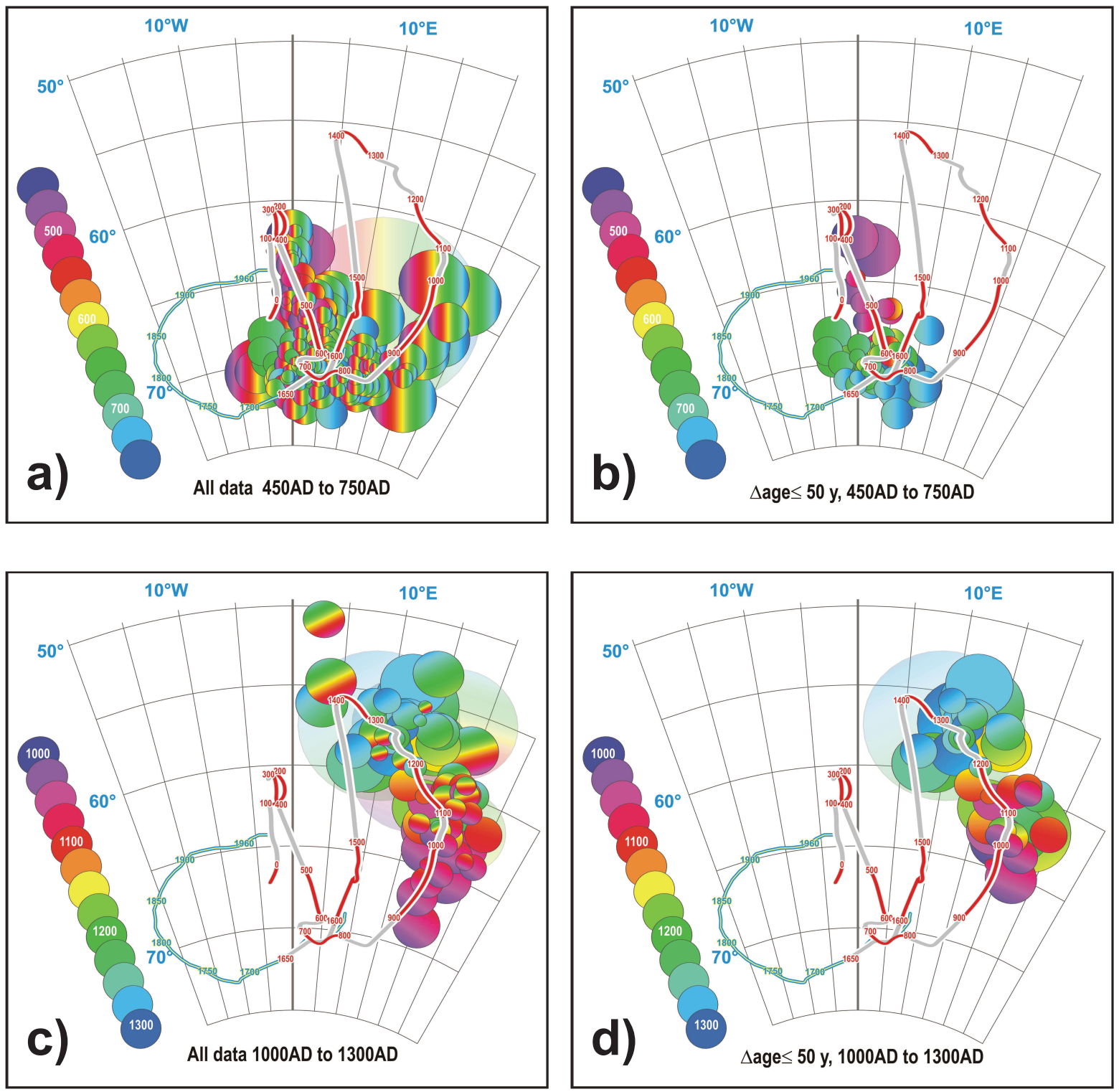

Figure 9 

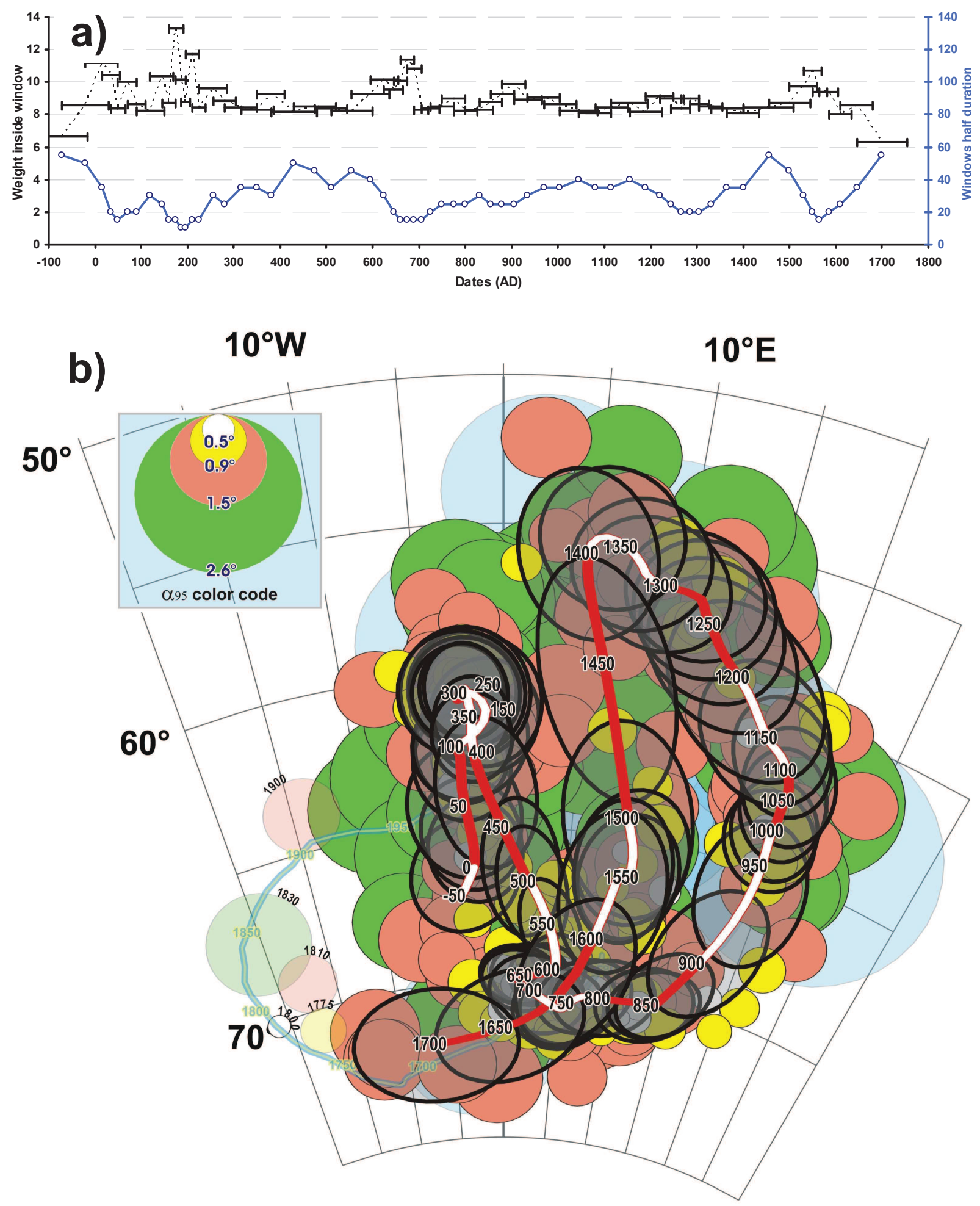

Figure 10 


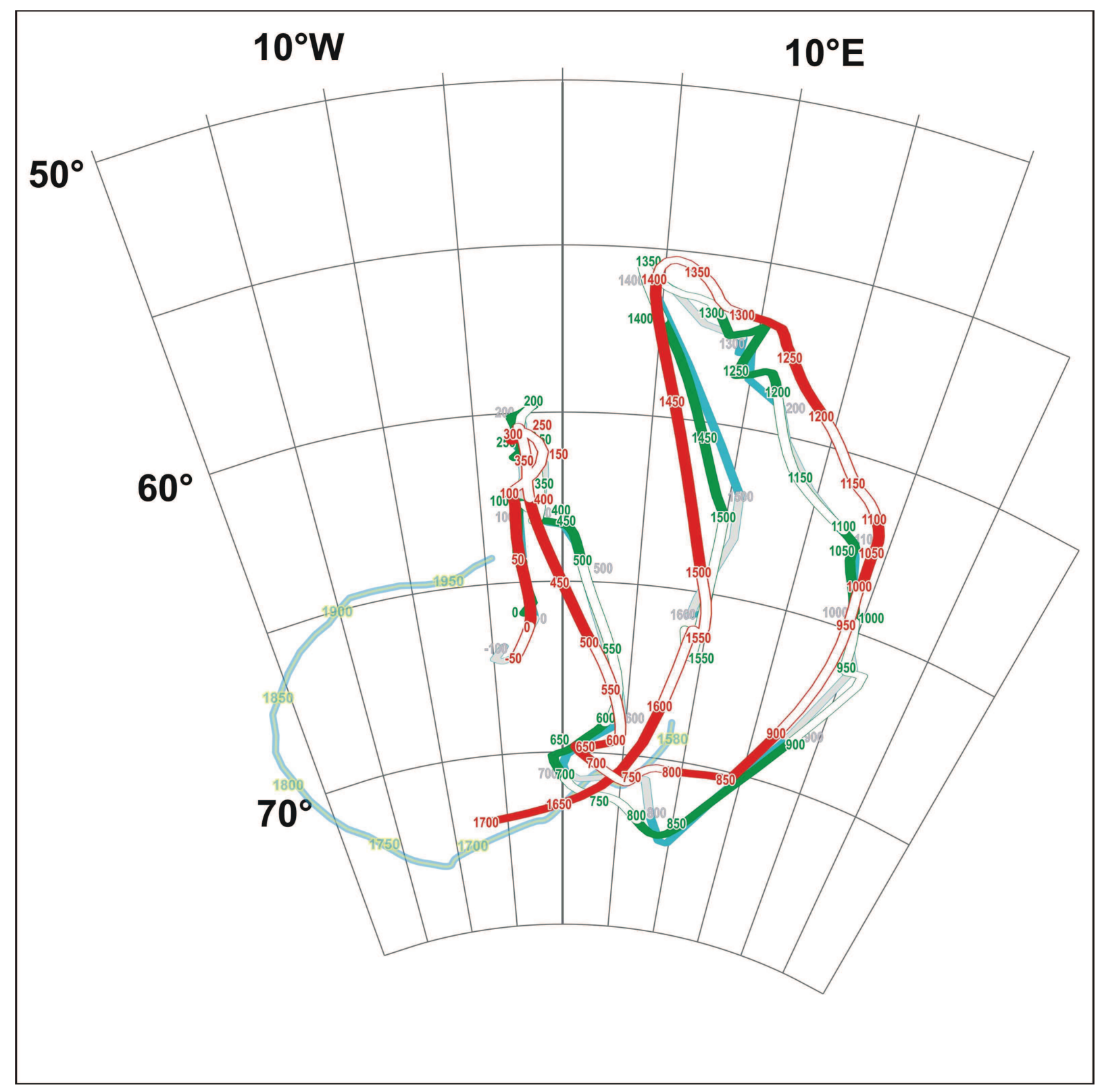

Figure 11 


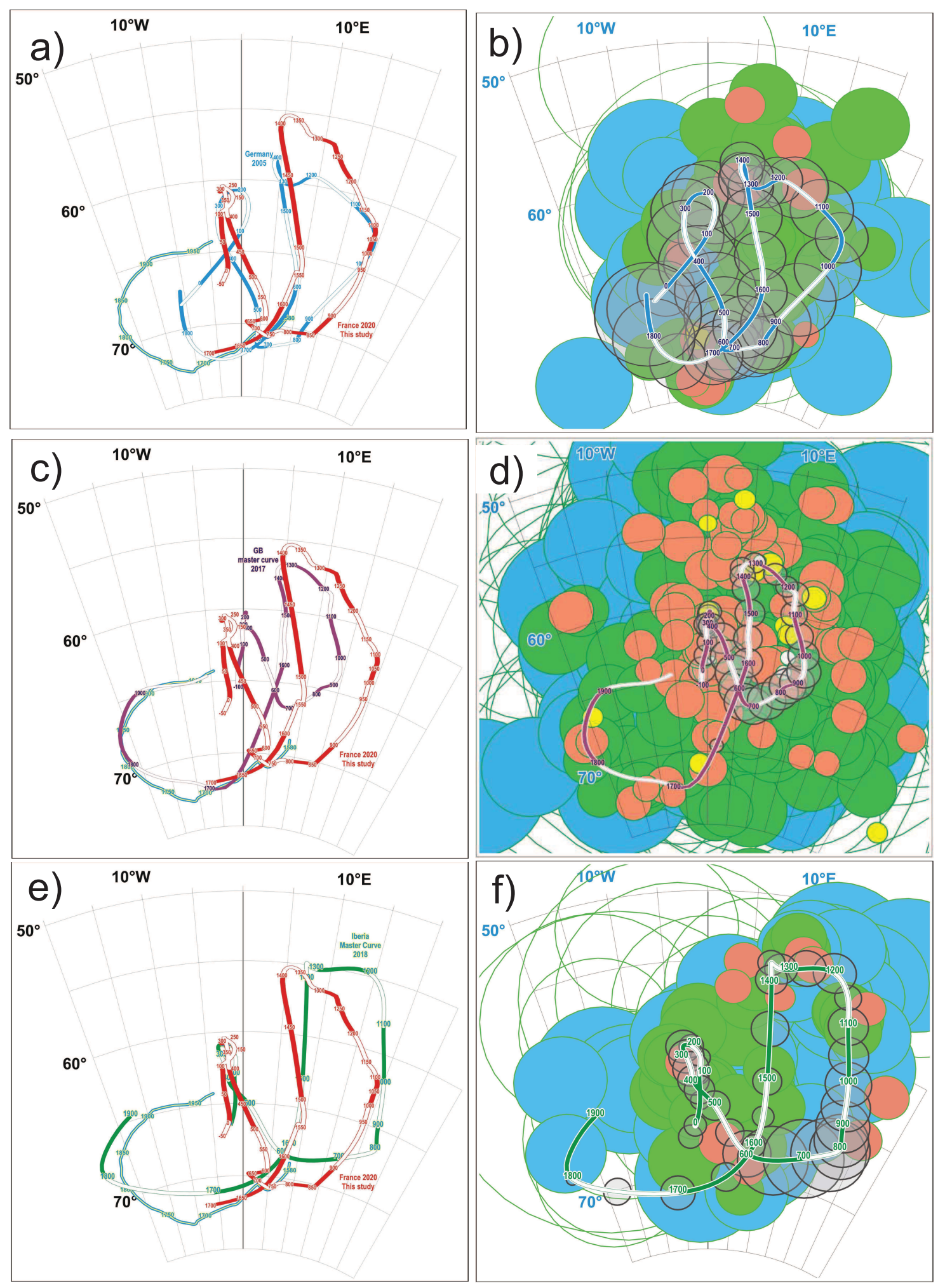

Figure 12 